Research Article

\title{
A Beacon of Space and Time: Detailed Depiction of Human Space in the Xiong'an New Area Guided by Material Cultural Heritages
}

\author{
Yingchun Cao $\mathbb{D}$, Jie Yang $\mathbb{D}$, Xiaoling Chen $(\mathbb{D}$, and Xiujuan Yang $\mathbb{D}$ \\ School of Architecture and Art, Hebei University of Architecture, Zhangjiakou 075000, China \\ Correspondence should be addressed to Yingchun Cao; xjyang@hbu.edu.cn
}

Received 3 June 2021; Accepted 14 July 2021; Published 4 August 2021

Academic Editor: Guangdong Wu

Copyright ( $) 2021$ Yingchun Cao et al. This is an open access article distributed under the Creative Commons Attribution License, which permits unrestricted use, distribution, and reproduction in any medium, provided the original work is properly cited.

\begin{abstract}
In April 2017, the Chinese government announced a plan to establish a national new district: the Xiong'an New Area (hereinafter referred to as Xiong'an). Xiong'an plays a major role in optimizing the layout of Beijing-Tianjin-Hebei city cluster, promoting the rapid development of regional cities and cultivating new drivers of innovative economy. As a result, Xiong'an is recognized in China as a millennium plan and a project with national significance. At this time, the scientific and forward-looking preliminary research work from more different fields will become important support to ensure the healthy development of Xiong'an. Taking the material cultural heritages of Xiong'an as a beacon, this paper makes a detailed depiction of the forms and features of the human space in Xiong'an in different stages during the ancient times. Multiple instruments were combined to realize the depiction, including archeological methods, geographical methods, and sociological methods. The results show that, on the vast North China Plains, with Baiyangdian Lake as the center, different social, political, and cultural factors have a huge impact on the social conditions, humanities activities, and heritage survival. Finally, based on the existing heritages, a visual projection was established between the ancient human space and the spatial distribution of potential heritages and used to predict the probability distribution of potential heritages in Xiong' an. The research results provide a scientific and forward-looking guide for the protection of material cultural heritages in the upcoming massive construction of Xiong'an.
\end{abstract}

\section{Introduction}

1.1. The Xiong'an New Area. In April 2017, the Chinese government announced a plan to establish a national new district: the Xiong'an New Area (hereinafter referred to as Xiong'an) [1]. Lying at the heart of Central Hebei Plains, eastern China's Hebei Province, Xiong'an is located right at the center of the triangle between Beijing (political center of China), Tianjin (economic center of northern China), and Shijiazhuang (seat of Hebei Province) (Figure 1). It is the hub of transport and functional, economic, and cultural exchanges between the three cities. The planning and construction of Xiong'an have profound realistic and historical significance for redistributing Beijing's noncapital functions, renovating the development model of populous economic-intensive areas, optimizing the layout and spatial structure of BeijingTianjin-Hebei urban cluster, cultivating innovative drivers of economy, and promoting the rapid development of regional cities [2]. On a larger scale, Xiong'an plays a major role in perfecting and balancing the layout and development of the three dominant urban clusters in China: Beijing-TianjinHebei, Yangtze River Delta, and Pearl River Delta [3]. That is why Xiong'an is recognized in China as a millennium plan and a project with national significance [2].

Xiong'an has a unique geographical environment. It is situated at a core area to the east of the Taihang Mountains, where the alluvial fan of the Daqing River converges with that of the Hutuo River [4]. The landform is dominated by plains, basins, and depressions. There are two large depressions in Xiong'an, namely, Baiyangdian and Wen'an (Figure 1). The rivers and lakes form a continuous corridor of wetlands [5], including the east-west transverse tributaries of the Daqing River and the large lakes from Baiyangdian to Wen'an in the middle and lower reaches of the river (e.g., 


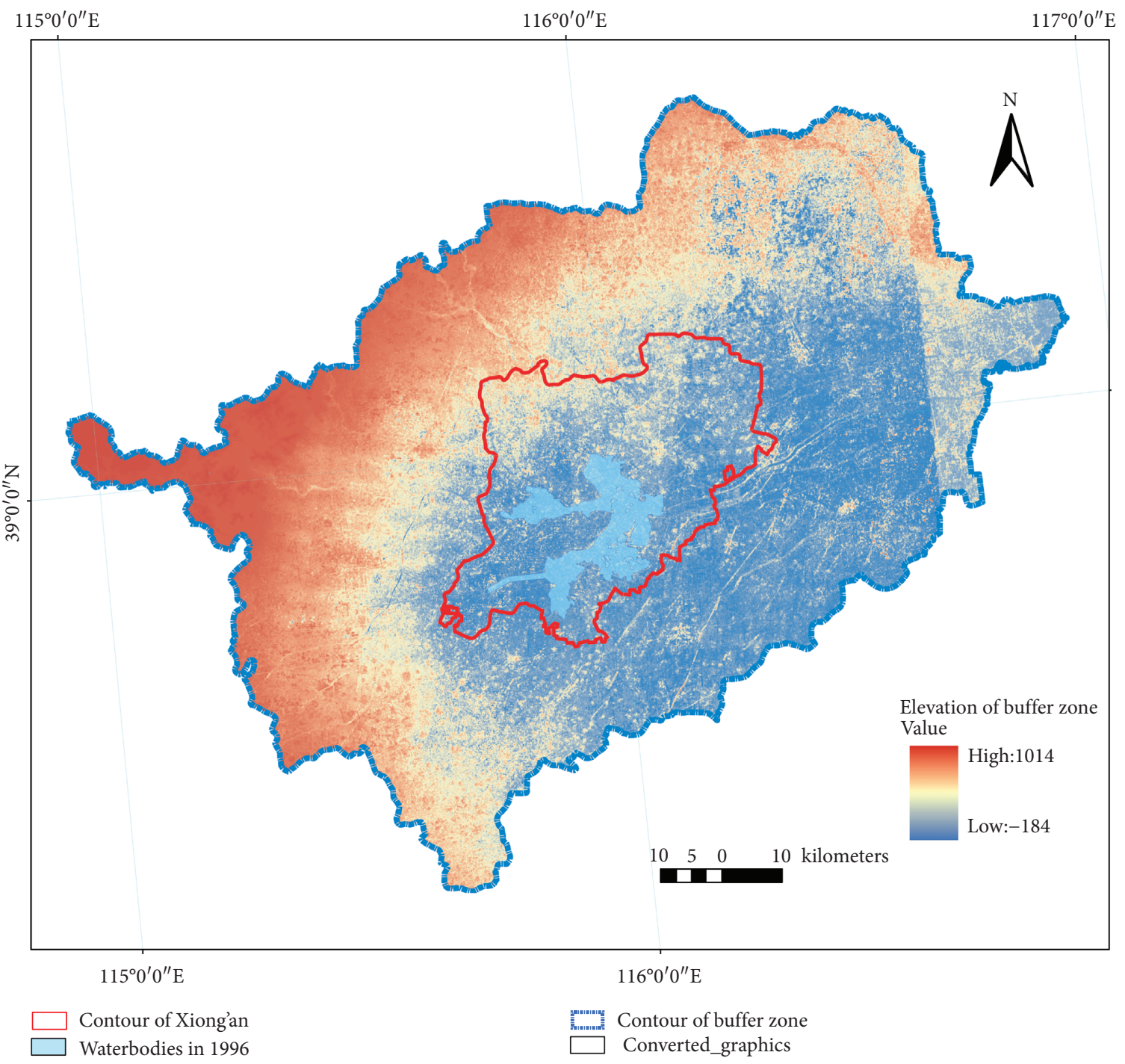

FIgURE 1: Topographic map of Xiong'an and its surrounding buffer zone.

Baiyangdian Lake, Wuguan Lake, and Desheng Lake). In the flood season, the flood water cannot be easily discharged in this corridor, causing frequent floods in history [6]. Therefore, the wetland corridor becomes a natural barrier to the north-south traffic in the Central Hebei Plains.

On the microscale, Xiong'an belongs to the north of Baiyangdian Depression. With an elevation of about 7-19 m, the entire area can be divided by the Rongcheng-Xiongxian line into the northwest highland and the southeast lakes and depressions (Figure 2). The southern margin of the northwest highland surrounds the northern Baiyangdian in three directions along the line from Anxin and Rongcheng to Xiong'an; the southeast lakes and depressions mainly refer to Baiyangdian Lake and a part of Wen'an Depression, which are crisscrossed by many ancient river channels and linear high banks [7].

From the perspective of time, the core of the geographic environment of Xiong'an is how the plains and depressions interact with the water in Baiyangdian. The evolution of the lake provides an important clue for the mesoscale shaping of the human space variation in Xiong'an. In the late early
Holocene (10,000-7,500 years ago), the ancient Baiyangdian gradually appeared and went through several cycles of expansion and shrinkage. Eventually, the contiguous water area was reduced into the multiple small waterbodies today [8] (Figures 3(a)-3(c)). As a result, early humans had the chance to enter the realm of the ancient Baiyangdian. In the following thousands of years, Baiyangdian expanded and shrank several times. The lake dried up in Han Dynasty and reappeared later. In general, the water area continued to reduce. In the 1990s, the water area variation of Baiyangdian was accurately captured by the emerging satellite mapping technology. The data show that the water area of the lake is greatly affected by basin management and natural rainfall (Figures 3(d)-3(f)) [9]. Referring to the data, it is possible to perceive how the water area of the ancient Baiyangdian changed and understand the ensuing human-water interactions: when the water level drops, people occupy the exposed land; when the water level rises, people retreat to highland. Currently, the water area of Baiyangdian is basically stable, roughly the same as it was in 1996 (Figure 3(e)). 


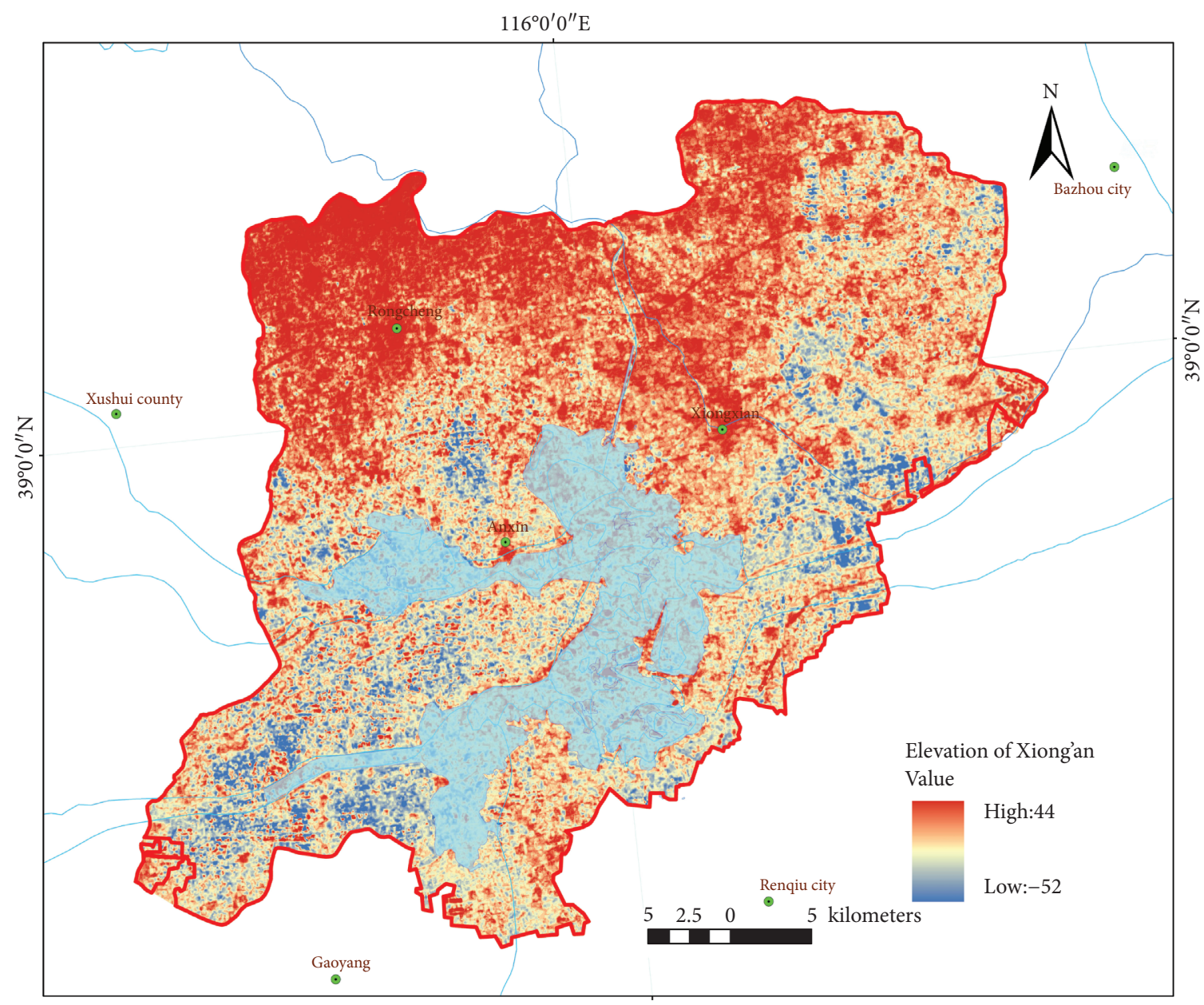

$116^{\circ} 0^{\prime} 0^{\prime \prime} \mathrm{E}$

Contour of Xiong'an

Waterbodies in 1996
Rivers on five levels (effectively projected)

Converted_graphics

FIgURE 2: Topographic map of Xiong'an.

1.2. Problem Statement. Xiong'an covers a vast area: the startup area is about $100 \mathrm{~km}^{2}$, the midterm development area around $200 \mathrm{~km}^{2}$, and the long-term control area roughly $2,000 \mathrm{~km}^{2}$. The magnificent planning and rapid construction are bound to reshape the geographic environment, urban structure, economy, and culture in the region fundamentally and quickly. Since the announcement of the plan, the government has been engaging in basic work like resource survey, afforestation, and river improvement in a prudent, systematic, and comprehensive manner, aiming to build a future city with high quality and standard [10]. Scholars also investigated and evaluated the evolution trend and sustainable development potential of Xiong'an, from the aspects of expansion and evolution of regional cities [11], simulation of urban function transfer [12], landscape Pattern Evolution [13], and evaluation of the ecosystem [14], which provided theoretical support for the future construction of Xiong'an. So far, the construction of transport infrastructure has been kicked off, including expressways and high-speed rails. In future, Xiong'an will enter the phase of large scale urban construction. At this time, the scientific, forwardlooking, and comprehensive preliminary research work from more different fields will become important support to ensure the healthy development of Xiong'an.

Regarding the archeology of material cultural heritages, the government has clearly defined the principle of "archeology first, groundbreaking second." Archeological investigations in Xiong'an were initiated early in 2017. The material cultural heritages of the region have been extensively surveyed and excavated [15]. Scholars have conducted relevant studies in a larger scale of time and space from the perspectives of cultural evolution [16], types of artifacts [17], and distribution of settlements [18]. However, the existing studies mainly focus on the macro history of the North China Plains or specific heritages. There is no technical result on the scale of Xiong'an that accurately guides heritage protection and planning construction. In terms of depth, almost no scholar has discussed the relationship between complex social factors and heritage survival. This is attributed to the lack of effective analysis tools in the field of 


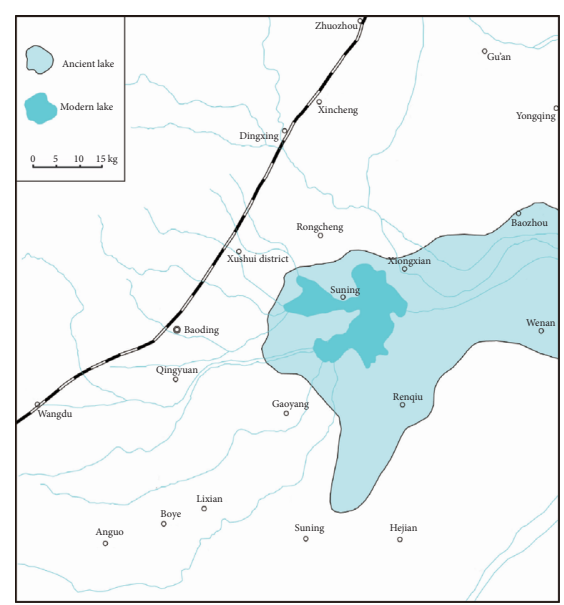

(a)

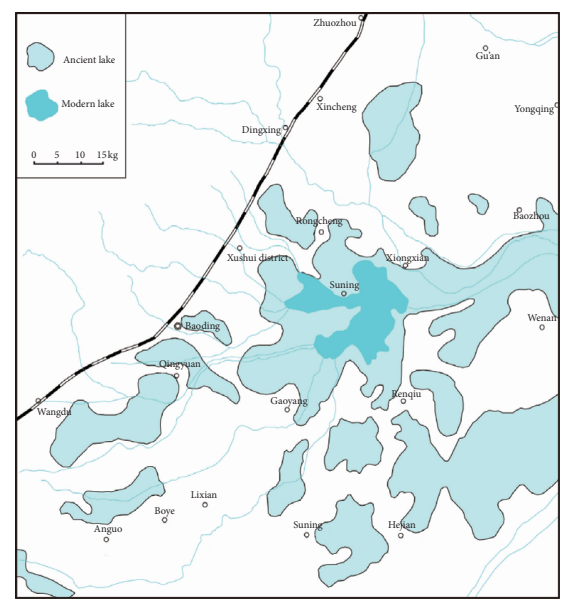

(c)

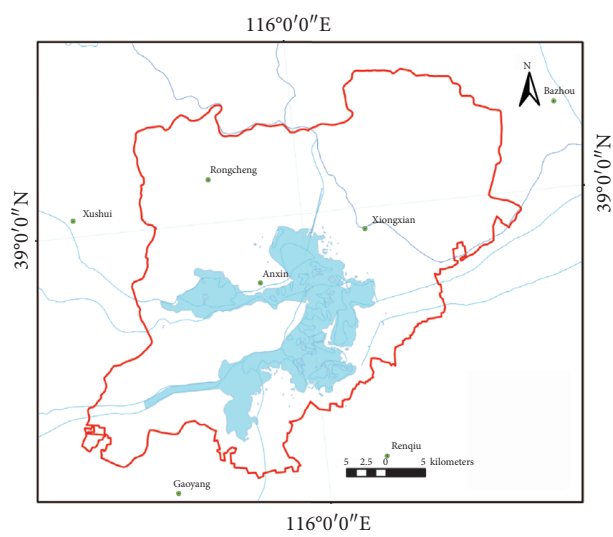

(e)

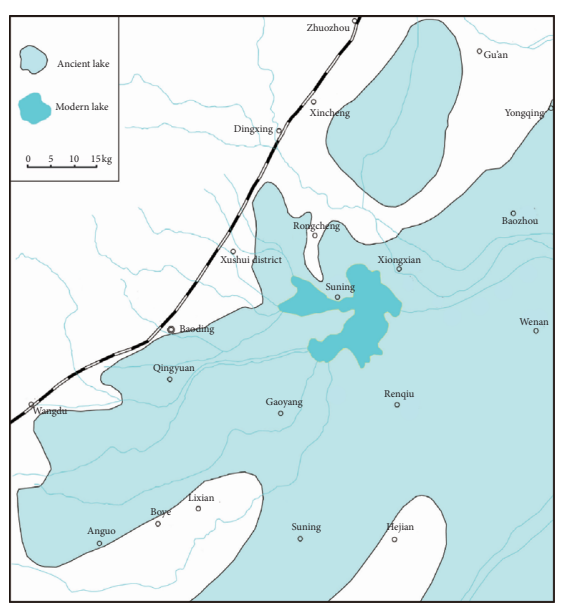

(b)

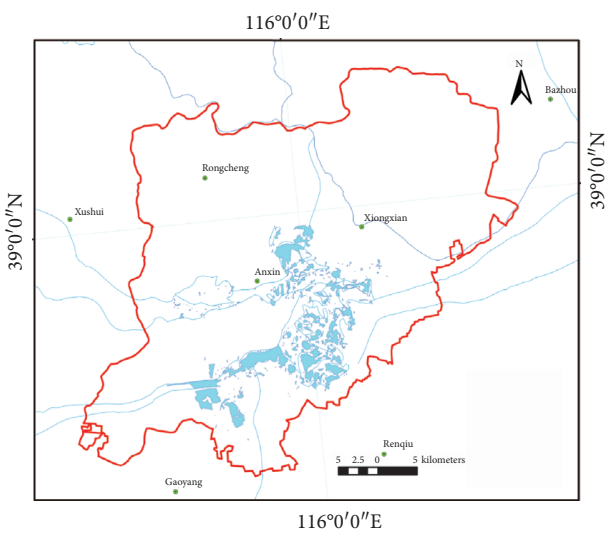

(d)

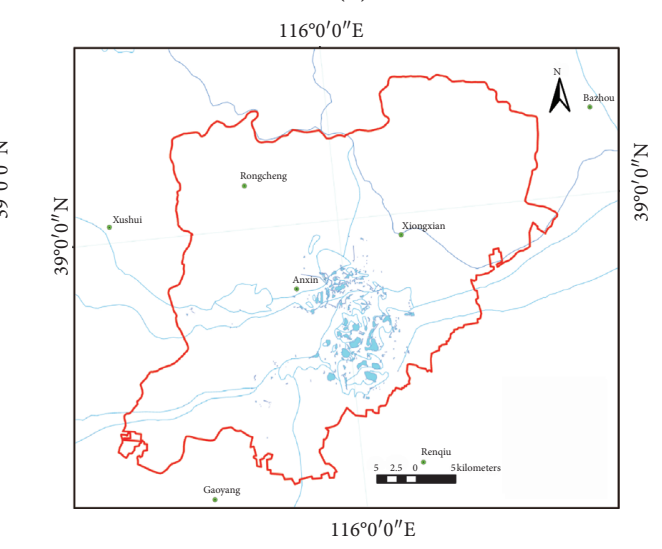

(f)

Figure 3: Water area variation of Baiyangdian. Note. Figures 3(a)-3(c) were plotted based on expansion and shrinkage of Baiyangdian in the past 10,000 years; Figures 3(d)-3(f) were plotted based on satellite images. (a) Baiyangdian revived in the early Holocene. (b) Baiyangdian expanded extremely in the middle Holocene. (c) Baiyangdian Lake disintegrated and shrank in the late Holocene. (d) Water area in 1992. (e) Water area in 1996. (f) Water area in 2002.

heritage protection. Heritage protection involves a lot of complex social factors. Some factors are quantitative, and some are qualitative. The traditional approaches of multifactor relationship analysis, namely, correlation analysis [19], regression analysis [20], and structural equation [21], cannot easily handle complex sociological issues, which have a small sample size, multiple concurrent causes and consequences, and qualitative variables. The relationship between social factors and heritage survival is the combined result of multiple concurrent causes and consequences. That 
is, the same phenomenon might be generated along several different paths. The causality is not linear and correlated, but complex and syncretistic.

Researchers in other fields of sociology have long noticed the issue of multiple concurrent causes and consequences and developed the qualitative comparative analysis (QCA), which overcomes the limit of traditional statistical analysis. The QCA examines the relationship between conditions and consequences from the angle of set theory, draws the causality of the topic from a small sample set using the Boolean algorithm, and investigates the composite paths and impact intensities of the causes for complex social phenomena [22]. Liu et al. [23] further proposed the fuzzy set QCA (fsQCA), which breaks through the limitations of binary variable analysis and adapts well to the depiction of complex continuous variables. Since then, QCA and its related methods have been widely adopted in economic operation [24], social employment [25], and work policy [26]. If it is introduced to study the relationship between social factors and heritage survival, the QCA can effectively disclose the composite paths and impact intensities of the causes for complex social phenomena, facilitating the deduction of the spatiotemporal distribution law of potential heritages in Xiong'an under the effect of multiple factors. The latter issue needs to be solved urgently before the construction of Xiong'an.

1.3. Research Aim. Taking the material cultural heritages of Xiong'an as a beacon, this paper makes a detailed depiction of the forms and features of the human space in Xiong'an in different stages during the ancient times. Based on geographical and sociological theories, the authors attempted to establish a visual projection between the ancient human space and the spatial distribution of potential heritages and relied on the projection to predict the probability distribution of potential material cultural heritages. The research results provide a scientific and forward-looking guide for the protection of material cultural heritages in the upcoming massive construction of Xiong'an.

\section{Research Scope, Data, and Methods}

2.1. Research Scope and Data. The time span was defined as the period from the Neolithic Age to the founding of New China. The spatial range belongs to two scales: (1) the administrative region of Xiong'an, which covers all the material cultural heritages in the region, was taken as the core area to be meticulously depicted (Figure 2); (2) the area extending from the core area to the neighboring counties by roughly the same distance was defined as the buffer zone (Figure 1). On the mesoscale, the core area is suitable for high-precision depiction. The buffer zone, covering the macro distribution trend of broader heritages, makes up for the defects of the systemic deficiencies of the core area.

The data were prepared based on the latest archeological results of material cultural heritages in Xiong'an. At the same time, the Atlas of Chinese Cultural Relics [27] was taken as a reference to ensure the consistency and completeness of the macro-trend research of material cultural heritages in terms of statistical caliber and archeological depth.

2.2. Research Methods. Multiple tools were synthetized in this research, including methods of archeology, geography, and sociology. This section focuses on the QCA and the technical flow. Archeological and geographical methods were not introduced, as they are very common.

QCA. The QCA is a sociological research method proposed by the American sociologist C. C. Ragin in 1987. Drawing on the idea of the set theory, the QCA integrates the merits of traditional quantitative research and qualitative research and examines the composite paths and influence mechanisms of the complex factors affecting social phenomena [28]. Currently, four QCA methods are available for solving difference cases. Among them, fsQCA is a configuration analysis instrument based on the comparison of multiple cases [29]. It is often used to test the relationship between the dependent variable (outcome variable) and the combination of multiple specific conditions. The condition combination with the highest coverage and consistency is called the optimal combination. Each condition combination (outcome combination) reflects the influence of different combinations between conditional variables on the outcome, when a single variable does not constitute a necessary condition of the outcome. This method can recognize the common configuration between multiple cases and provide multiple equivalent paths for the same outcome, i.e., the multiple combinations between several equivalent antecedents that lead to the same outcome. The fsQCA applies to the cases with complex conditional variables that have complex values. The value ranges of these variables often contain a median and cannot be simplified as 0 or 1 [30]. This paper selects fsQCA as the analytic tool, in view of the complexity and qualitative values of the factors affecting the social evolution in Xiong'an in the ancient times.

By summing up the historical data, seven key factors affecting the development of each dynasty in ancient Xiong'an were selected as the conditional variables: population situation, location importance, war turbulence, business exchange, agricultural prosperity, folk culture, and water area. In addition, the social development and heritage number in the corresponding stage were taken as the outcome variables. After that, the conditional and outcome variables were subjected to six-level calibration and value assignments, according to the value assignment standard in Table 1 and the indirect calibration method. The optional values include $0,0.2,0.4,0.6,0.8$, and 1 [31]. Next, the consistency and explanatory power of each variable were calculated by QCA. The consistency can be calculated by

$$
\text { Consistency }\left(X_{i} \leq Y_{i}\right)=\frac{\sum\left[\min \left(X_{i}, Y_{i}\right)\right]}{\sum X_{i}} .
$$

The coverage can be calculated by [32], 
TAвLE 1: Fuzzy set values of each variable.

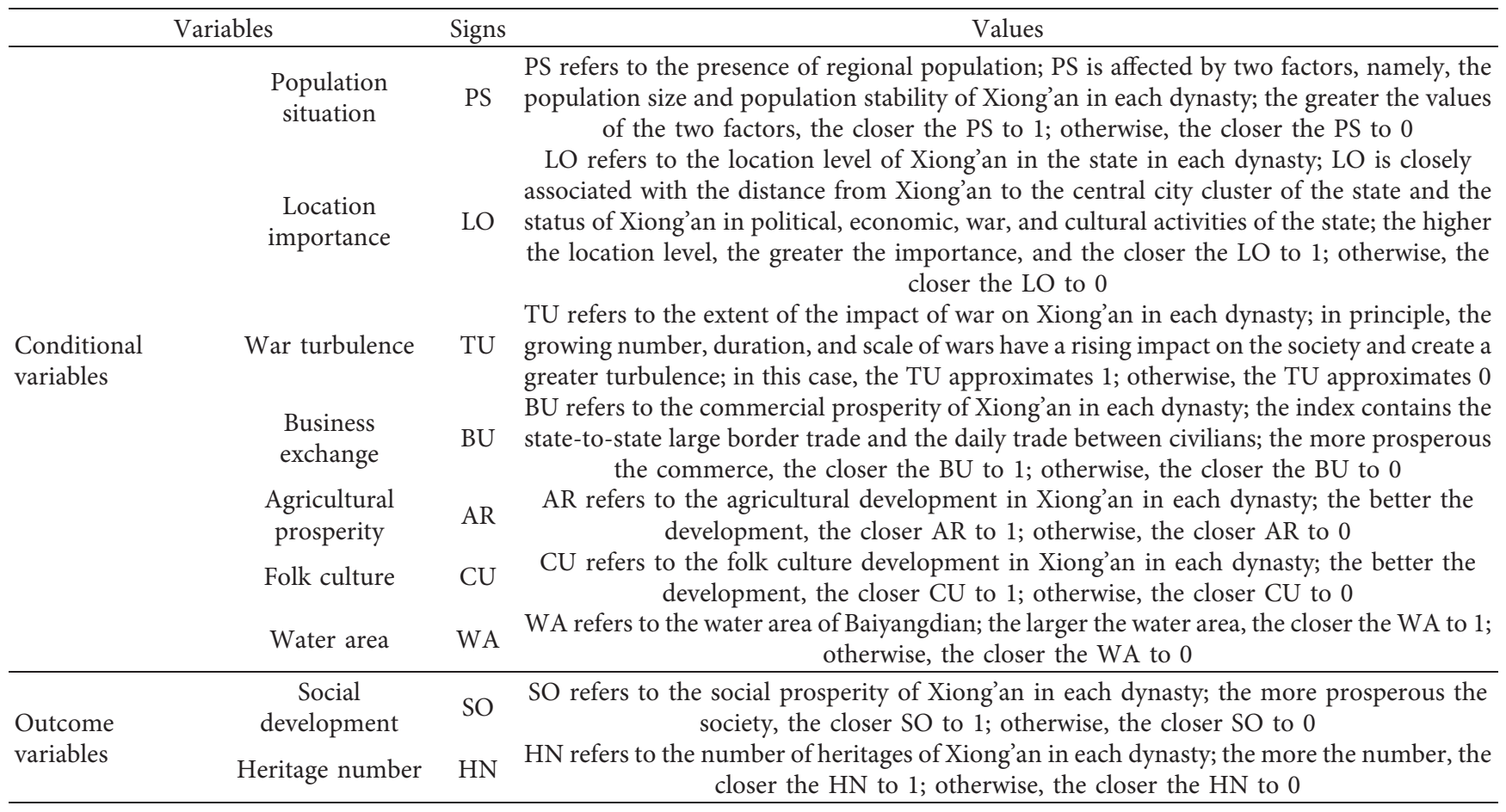

$$
\text { Consistency }\left(X_{i} \leq Y_{i}\right)=\frac{\sum\left[\min \left(X_{i}, Y_{i}\right)\right]}{\sum Y_{i}},
$$

where $X_{i}$ is the degree of membership in set $X ; Y_{i}$ is the degree of membership in set $Y ;\left(X_{i} \leq Y_{i}\right)$ is the subset relation in question; and "min" dictates selection of the lower of the two scores.

The necessary or sufficient conditions were examined for each variable, and the explanatory power of each condition for each outcome was measured. If consistency is greater than 0.9 , the condition is a necessary condition of the outcome. If the fuzzy set score of the condition is smaller than that of the outcome and the consistency is greater than 0.8 , then the condition is a sufficient condition of the outcome [33]. Coverage measures the explanatory power of a condition for an outcome. The greater the coverage, the more the explanatory power. Finally, the combination of conditions was analyzed, and the combination path of various conditions was comprehensively investigated.

Technical flow. The technical flow of our research can be summarized as follows. Guided by material cultural heritages, geographic spatial analysis [34] was supplemented by historical data and modern research results to visualize the state and trend of heritage distribution and depict the human space with a high accuracy. Next, QCA was performed to further analyze the necessity and configuration of the multiple factors that affect the ancient social development and existing heritage number in Xiong'an. Finally, based on the existing material cultural heritages, the spatial range of each type of potential heritages was calculated, using the theories of Kriging [35], spatial accessibility [36], and spatial relationship of settlements [37]. The time sequence and type probability of heritages were assigned by the QCA results, producing the final probability distribution of potential heritages. The main technical points and roadmap (Figure 4) are as follows:

(1) Archeology is a continuously updated dynamic process. The above probability distributions are all derived based on the current archeological information. With new discoveries in future, the distributions should be corrected and improved to approximate the truth.

(2) The social condition and behavior space of each type of heritages in each stage are the basis of prediction. The scope is determined in the following steps: taking each known heritage as the sign (dot or line), the mean spatial distance of the corresponding cultural behaviors is taken as the step length $D$. Then, the distance is expanded by $D$ or $1.5 D$ (the larger envelope scope) to estimate the scope of existence for adjacent potential heritages of the same type or correlated types. The heritage is the crux of the prediction for the distribution of each type of heritages. The prediction is particularly accurate based on the heritages before Qin dynasty, because they were not clearly divided into different types of heritage at that time.

(3) The probability, density, and level of the grid image are all positively correlated with the distance to cultural core (extremely high area of heritage density). Taking density as example, the denser the type 


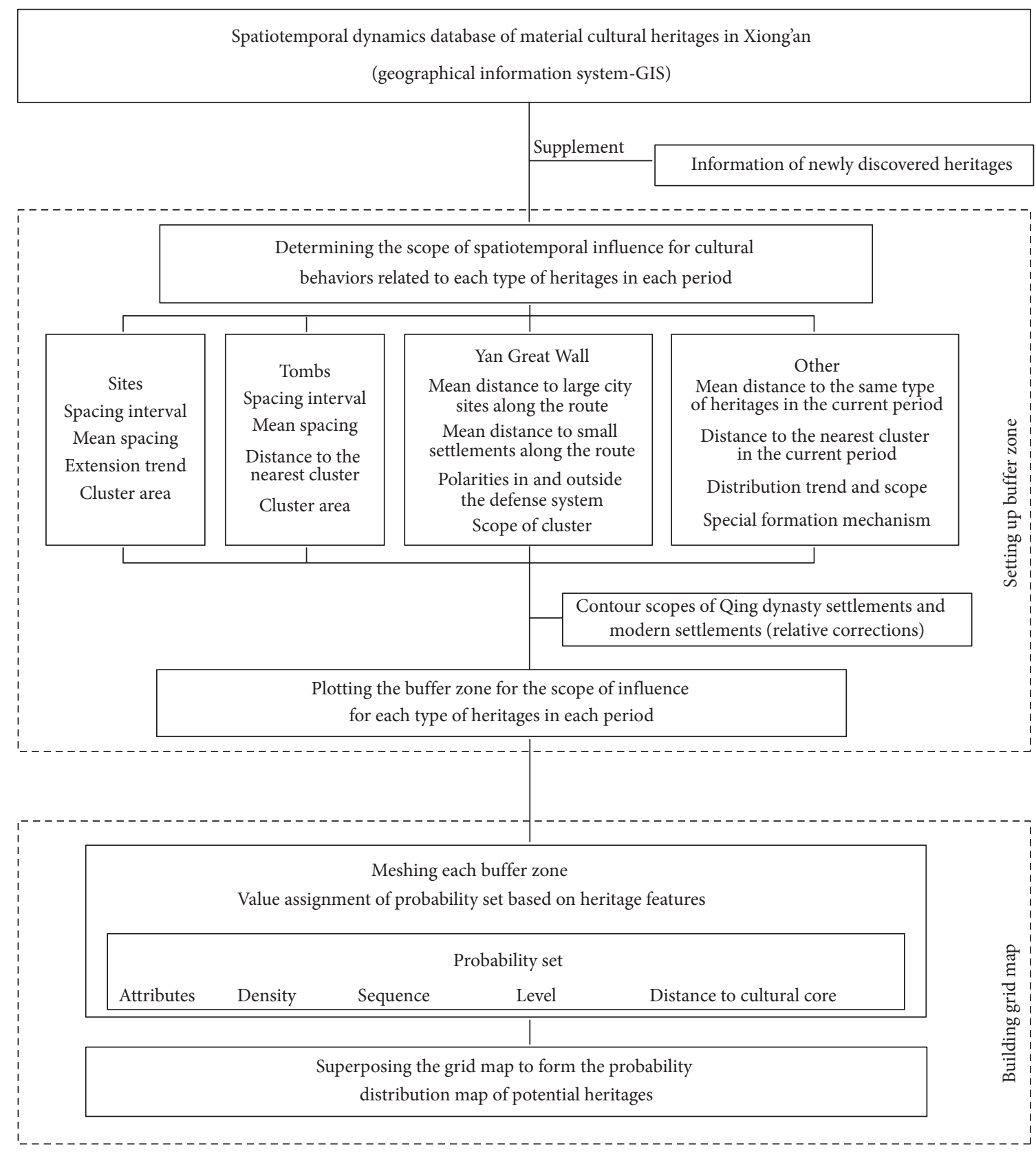

FIgURE 4: Technical roadmap.

of heritages in a period, the greater the probability of discovering potential heritages of the same type or correlated types in its surroundings. The time sequence and type probability of heritages were determined according to the factors affecting heritage number and the correlation between different types of heritages. The latter two were obtained through QCA.

(4) Because Qing Dynasty settlements well match modern settlements, the latter are adopted to assist the judgment of the distance from material cultural heritages (especially nonsite heritages) to adjacent settlement space. This facilitates the rough valuation of heritages under the lack of references.

\section{Analysis}

3.1. Statistical Analysis. The latest survey shows that Xiong'an has a total of 263 heritages, including 189 sites, 43 tombs, 15 ancient buildings, and 16 modern cultural relics. Besides, some heritages discovered in the last century but destroyed today are also included. Therefore, there are a total of 285 heritages in Xiong'an (Figure 5): 110 in Rongcheng, 85 in Anxin, and 90 in Xiongxian (Rongcheng, Anxin, and Xiongxian are three counties entirely or partly administered by Xiong'an). The latter two counties include the towns and townships under their administration.

As of 2019, Xiong'an had 3 national heritages, 9 provincial heritages, and 80 plus prefectural and county-level 


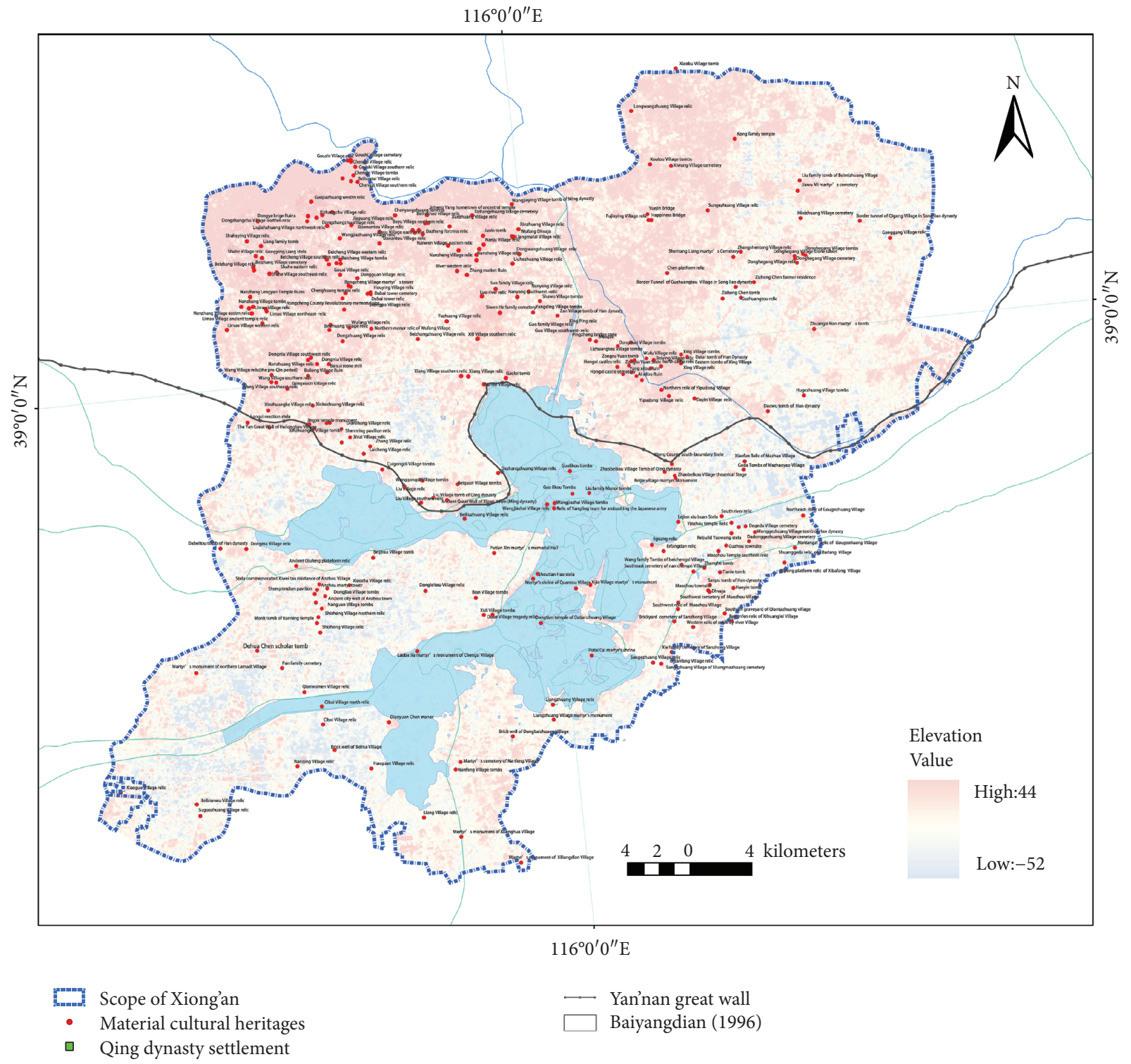

Figure 5: Distribution of material cultural heritages in Xiong'an.

heritages. These heritages mainly belong to sites, tombs, buildings, and revolutionary heritages. Most of them are sites $(58 \%)$ and tombs $(24 \%)$. The heritage distribution is basically the same in the three counties (Figure 6), a sign of the consistency in geography and culture. It is clear that Rongcheng boasts the largest number of sites, mainly because the high ground in the north is suitable for living.

With the elapse of time, the number of heritages oscillated significantly. Most of them were produced in the Spring and Autumn Period and Han Dynasty. Some were produced in Song Dynasty, Qing Dynasty, and the modern period. Very few were produced in Tang and Yuan Dynasties. The rest were produced in other periods (Figure 7). The time distribution density of heritages was slowly increasing, with local fluctuations. In modern times, numerous heritages were discovered in a short time. Without considering them, the time distribution density still rose in the modern period. Specifically, the number of material cultural

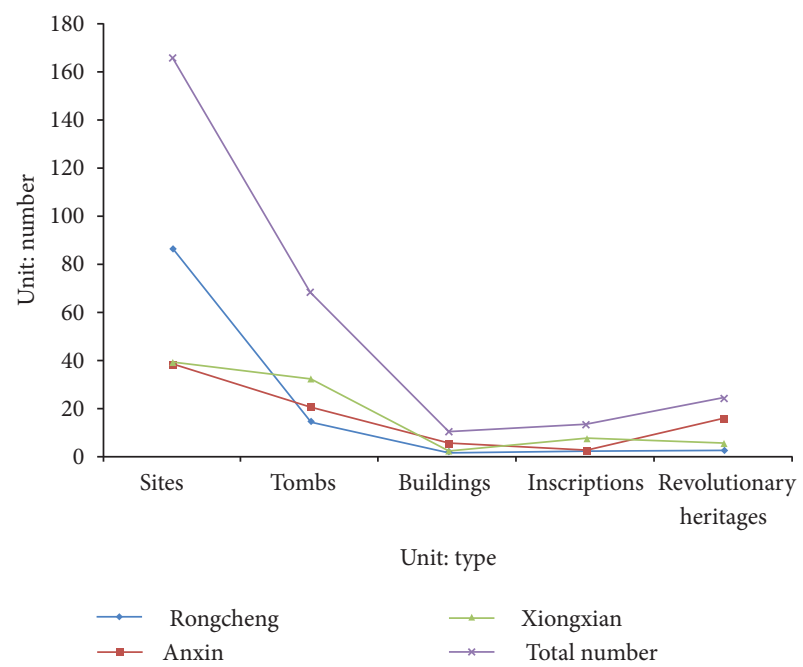

FIgURE 6: Number of material cultural heritages of each type. 


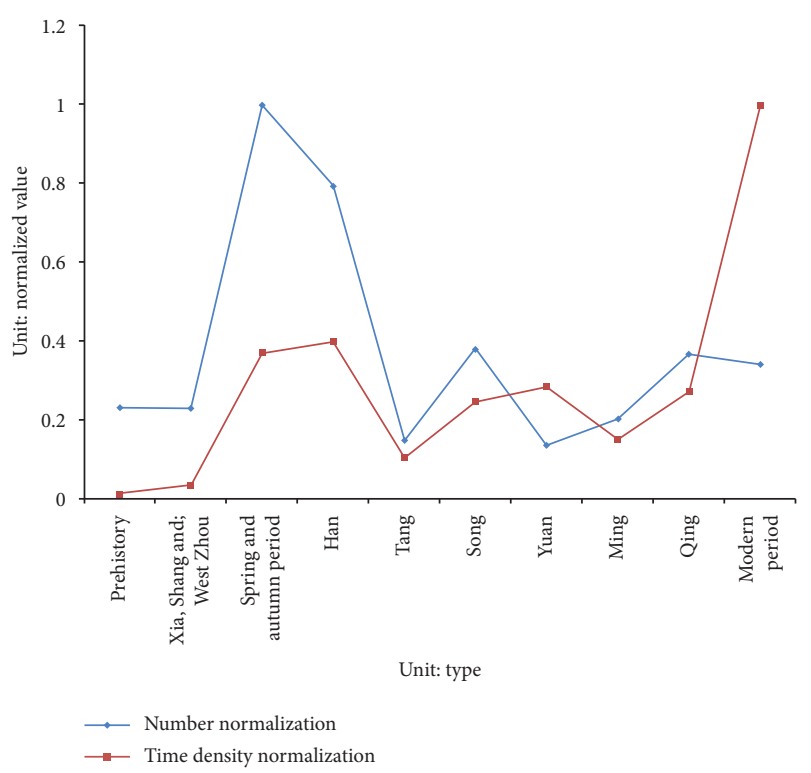

Figure 7: Mean time distribution density of heritages in each period (normalized).

heritages in Xiong'an remained stable and increased slowly before the East Zhou Dynasty, surged up from the Spring and Autumn Period to the Han Dynasty, nosedived in Tang Dynasty, steadily bounced back in Song Dynasty, slightly increased before plunging in Yuan and Ming Dynasties (in particular, Ming Dynasty had very few heritages, a stark contrast to its unification and vibrant culture; it is probably the result of the relatively small research scale), increased clearly in Qing Dynasty (a sign of advanced culture), and stayed at a moderate level in modern period.

3.2. Spatiotemporal Distribution. The heritages mainly concentrate in the northwest and middle parts of Xiong'an and almost encircle Baiyangdian Lake. Most heritages form three clusters, except a few scattered along the terrain or water surface in the northeast and south (Figure 8). The three clusters are as follows:

(1) There is a C-shaped cluster encircling the convex north margin of Baiyangdian Lake, which encompasses two belts of densely distributed heritages: the west belt starts from Rongcheng and spans to Dongxiaoli and Anxin in the south; the east belt extends from Rongcheng to Xiongxian in the east. This cluster is the core gathering area of material cultural heritages in Xiong'an. The two peak density nodes, namely, Rongcheng and Xiongxian, both fall in this cluster.

(2) There is also a medium density cluster centering on Mozhou Town, which lies on the east margin of Baiyangdian Lake.

(3) There is another dotted medium density cluster centering on Anzhou Town, which lies on the west margin of Baiyangdian Lake.
The three clusters are polarized in distribution trend. From the northwest to the southeast, the heritages exhibit a trend of integrating into Baiyangdian Lake; from the northeast to the southwest, the heritages are discretized at random. The superimposed elevation shows that the polarity is consistent with the lay of the land in Xiong'an. The above clusters agree well with the linear or dotted highlands.

On a small scale, individual heritages are attached to the relative highlands in the microscopic region. Only a few Han tombs appear in the low-lying areas of Baiyangdian Lake.

On a large scale, there are more heritages on the peripherals than in the middle of the buffer zone, except that the heritages are sparsely distributed in Gaobeidian and Gu'an in the north. The density distribution takes the shape of a bowl, i.e., high on the four sides and low at the center (Figure 9). However, the distribution is not continuous: an island-like area of ultrahigh median appears at the center of the bowl, and blank rings exist between the inside and outside. The island shape and symmetry of the ultrahigh median area indicate that Baiyangdian Lake, as the heterogenous element on the homogenous plains, exerts a cumulative disturbance to the normal social mode of Xiong'an, creating a unique cultural area. Judging by the type and distribution state of heritages, primitive heritages (Figure 10(b)), urban heritages (Figure 10(f)), and revolutionary heritages (Figure $10(\mathrm{~g})$ ) were the only types that made medium contributions. The other types of heritages made very little contributions. These three kinds of heritages are closely related to the attributes of Baiyangdian. The primitive heritages originated in the primitive society, thanks to the high elevation in the north of the lake; the urban heritages appeared as Xiong'an rose to prominence as a border trade hub during the Song Dynasty, because the Baiyangdian water system creates a natural border between Song and Liao; and the revolutionary heritages are the result of the fact that Baiyangdian is the only region in the Northern Hebei Plains that provides natural shelters for revolutionists. To sum up, the unique attributes and distribution pattern of heritages stem from the unique environment.

According to the sequence of evolution, the authors investigated the trend of the spatiotemporal distribution of heritages by drawing the ellipses of standard deviation [38] for the directional distribution of heritages in each and every stage, as well as the mean centers [39] (Figure 11). Throughout history, the ellipses cover the entirety of central Xiong'an. The superposition of the ellipses is close to a circle, with very weak polarity. This means the core distribution area of heritages is highly correlated with Baiyangdian Lake and testifies the fact that the polarities of heritage distributions in different periods cancel out each other after superposition. Therefore, important information could be covered up if the heritages of multiple stages are adhered together. To mine heritage information, a key prerequisite is to divide the history into multiple spatiotemporal slices.

The ellipses of different periods show significant differences in polarity and carry prominent features of the time.

In the Neolithic period, the ellipse is small and narrow and strongly skewed towards Baiyangdian Lake. In addition, 


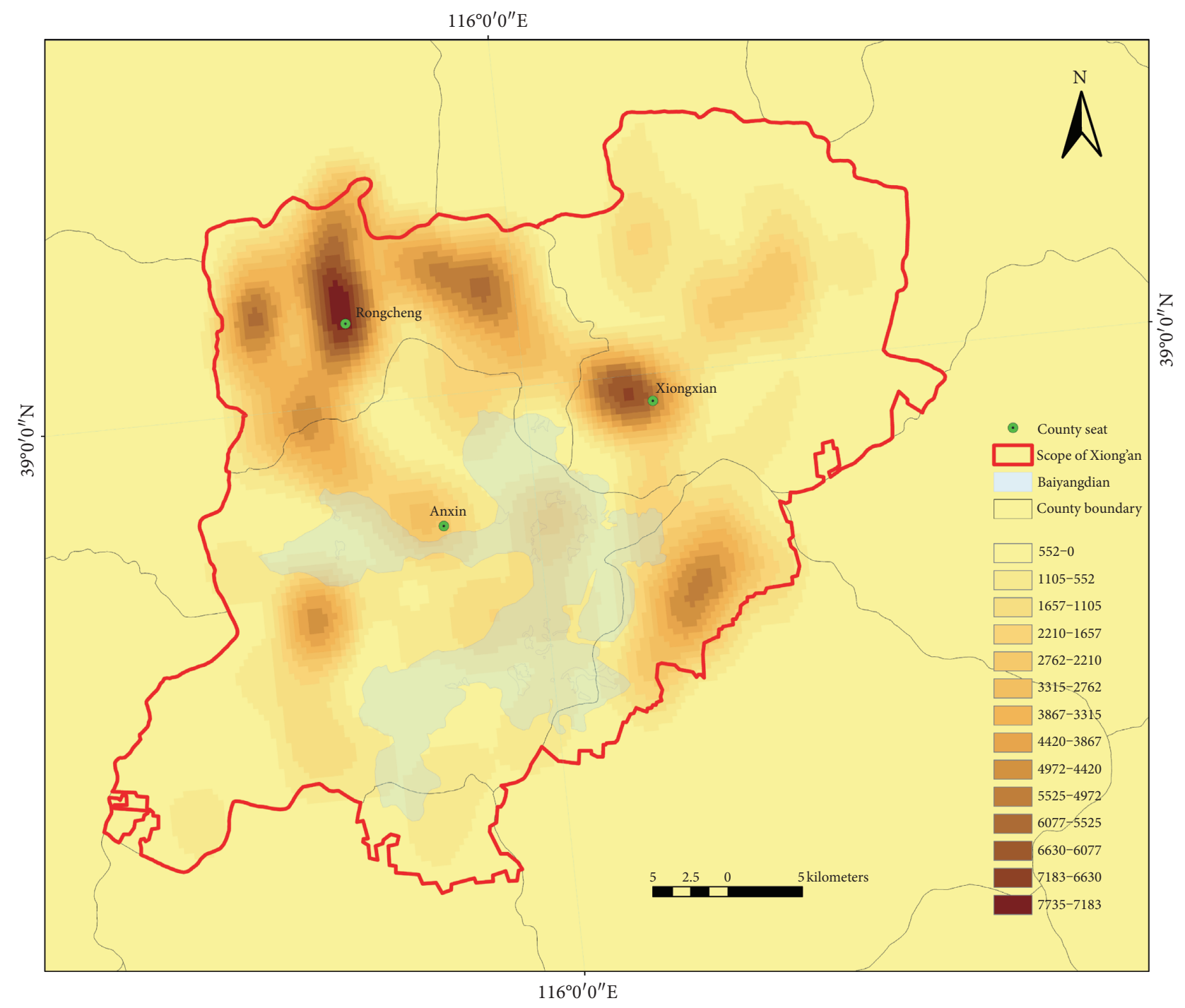

FIgURE 8: Density distribution of material cultural heritages.

it agrees well with the line from Rongcheng and Dongxiaoli to Anxin. The distribution center lies close to the Shangpo site in Rongcheng.

In Xia, Shang, and West Zhou Dynasties, the ellipse is of similar scale to that of the previous period. The location remains basically unchanged, still centering in Shangpo. However, there is a major change in directional polarity: the dominant axis becomes almost perpendicular to the northeast-southwest direction in the Neolithic period.

In East Zhou Dynasty, the ellipse expands and increases in directional polarity. The expansion takes place along the line from Rongcheng to Mozhou. The two places must have close correlations. The center of the ellipse is adjacent to Nanyang site.

In Han Dynasty, the ellipse expands significantly into a plump form, involving most of Baiyangdian Lake. The expansion in the east-west direction is further enhanced. The center shifts southward into Baiyangdian Lake, about $9 \mathrm{~km}$ to the then county seat (Guxian Village).
In Tang Dynasty, the ellipse has a moderate form but a rather large scale. From northeast to southwest, the ellipse spans across Baiyangdian Lake. The center moves to a place near downtown Anxin, which is related to the ultradiscrete distribution of heritages.

In Song Dynasty, the ellipse has a moderate form and a slightly smaller scale than that in Tang Dynasty. From northeast to southwest, the ellipse spans across the north and center of Xiong'an. The center falls at somewhere near the shore in the north part of Baiyangdian Lake, about $8 \mathrm{~km}$ to Xiongxian.

In Yuan Dynasty, the ellipse retreats to the northern highland of Xiong'an. The form is moderate, and major axis is in east-west direction. The center seems to be leaving Baiyangdian.

In Ming Dynasty, the ellipse is as plump as a circle, with a significantly reduced scale. However, it moves back to the hinterland of Xiong'an, centering at a similar place to the ellipse of Song Dynasty. 


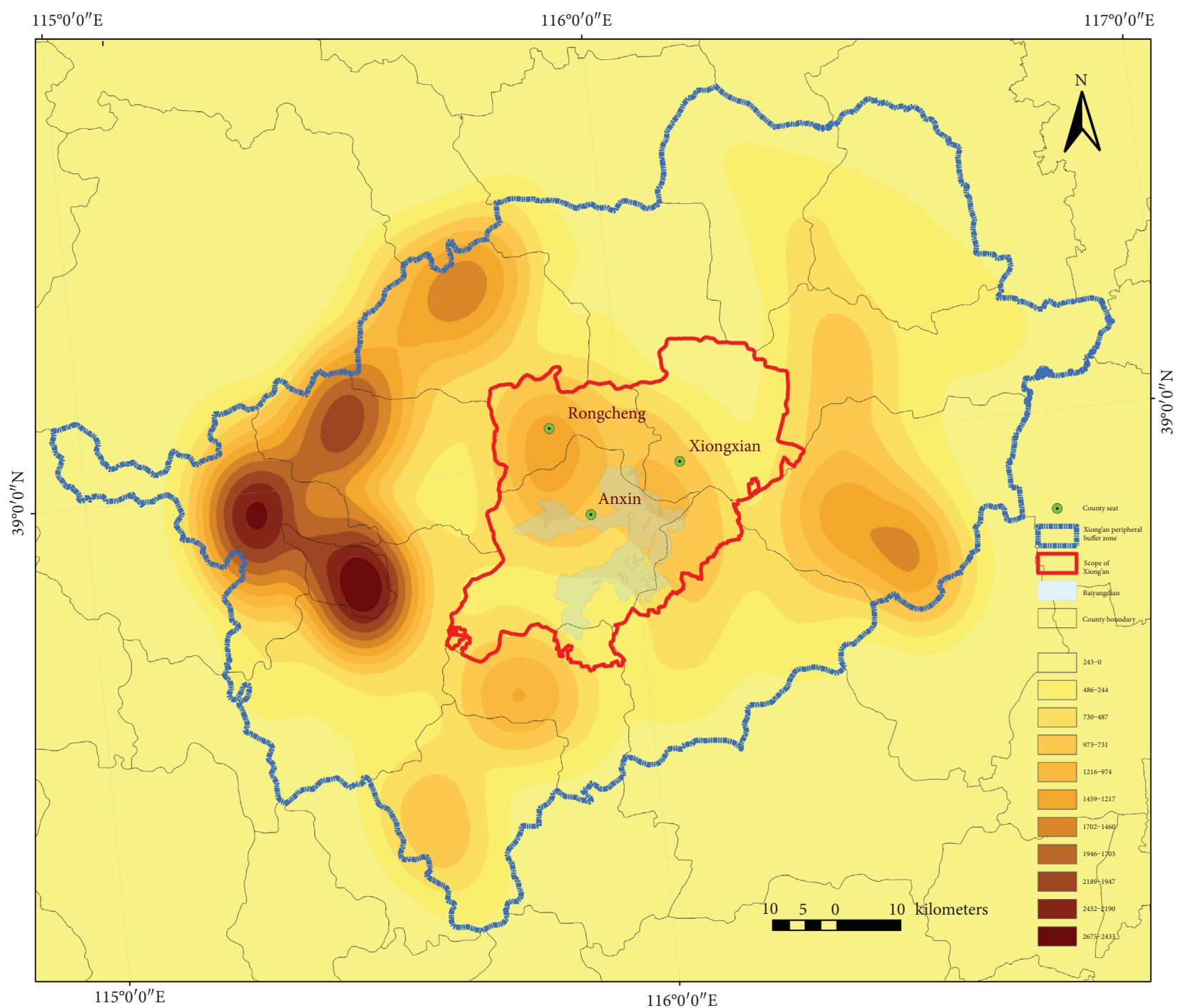

FIgURE 9: Density distribution of material cultural heritages in neighboring counties.

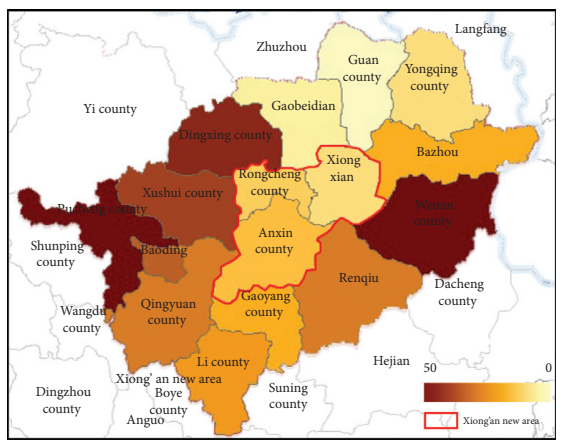

(a)

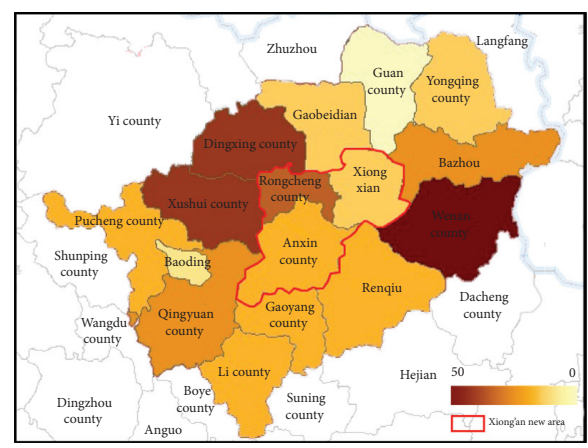

(b)

Figure 10: Continued. 


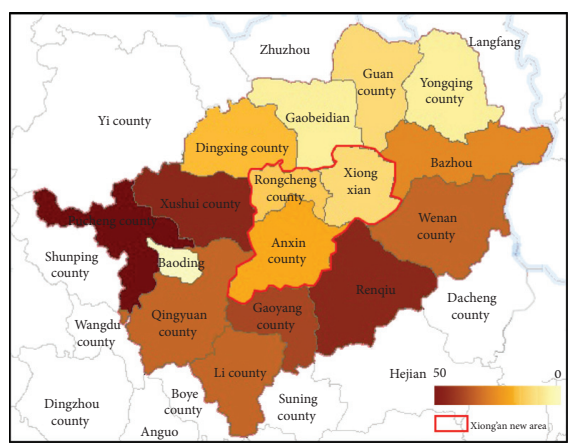

(c)

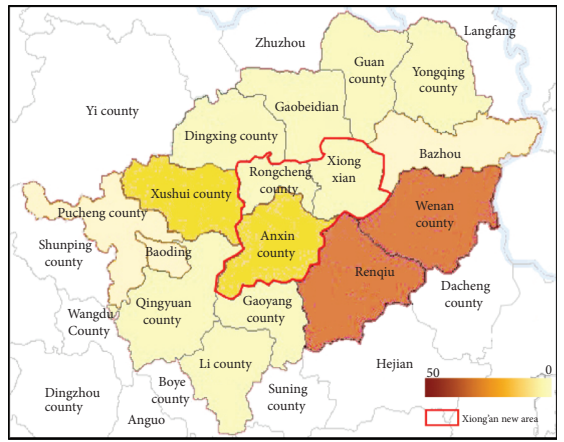

(e)

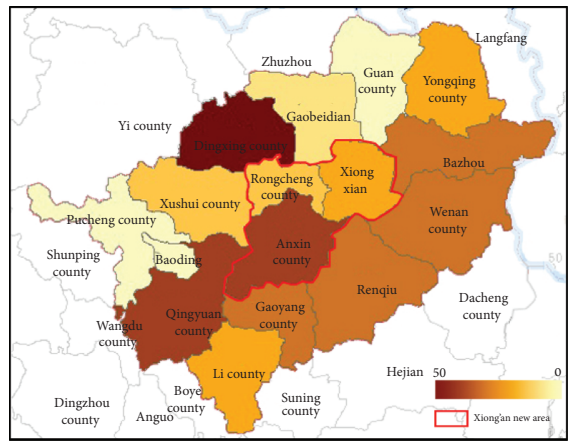

(g)

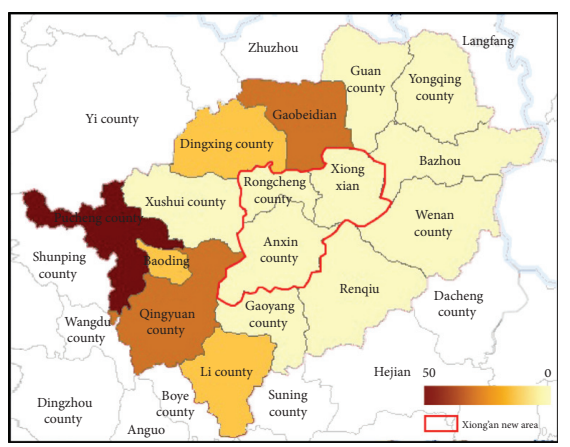

(d)

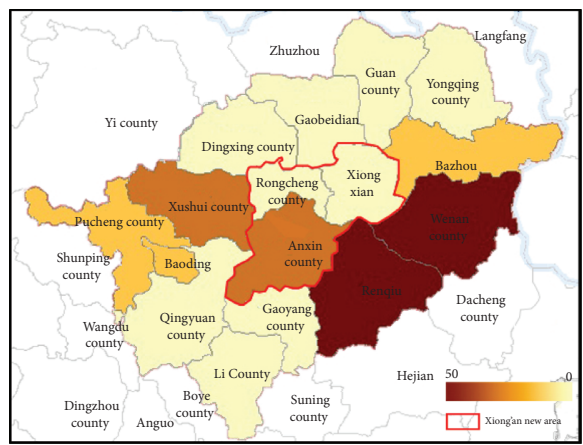

(f)

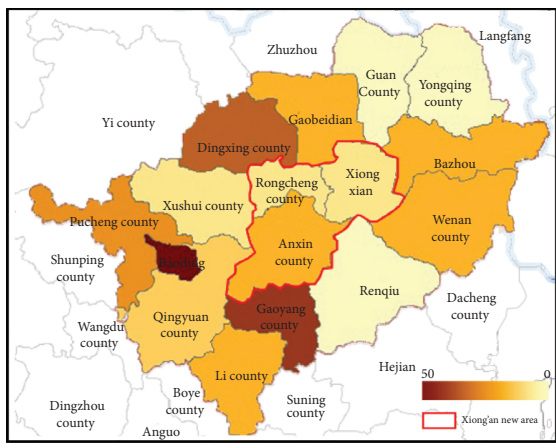

(h)

Figure 10: Number of heritages in and around Xiong'an. (a) All heritages. (b) Sites. (c) Tombs. (d) Bridges. (e) Inscriptions. (f) Cities. (g) Revolutionary heritages. (h) Buildings.

In Qing Dynasty, the ellipse has a moderate scale and polarity. The coverage is skewed slightly from the center to the northwest. The center moves close to the shores to the north of downtown Anxin.

During the Chinese People's War of Resistance against Japanese Aggression (hereinafter referred to as the War of Resistance), the ellipse is so large as to cover almost every inch of Baiyangdian Lake. The center lies deep in the lake. Moreover, the ellipse contour is highly in line with the water area.

3.3. Correlation Analysis. Referring to the local chronicles of Qing Dynasty and modern place names, the authors drew the distribution map of Qing Dynasty settlements. Besides, the contour map of modern settlements was plotted based on satellite images. Once the two maps were superimposed, it was learned that Qing Dynasty settlements are distributed similarly as the modern ones (except for being a little bit sparser in the northeast (Figure 12)), indicating that the pattern of modern settlements has been formed at least in the late phase of the reign by Emperor Qianlong.

In addition, the distribution patterns of material cultural heritages and Qing Dynasty settlements are very similar, but the latter fill up more blanks. Therefore, material cultural heritages mostly concentrate in the backbone area of densely populated settlements, proving the theoretical assumption that cultural activity is positively correlated with the probability distribution of settlements and population.

Furthermore, the distribution patterns of material cultural heritages and modern settlements are close to each other. The heritage density is positively correlated with settlement level. Most heritages appear on the edges or peripheries of villages and small towns. The heritages associated 

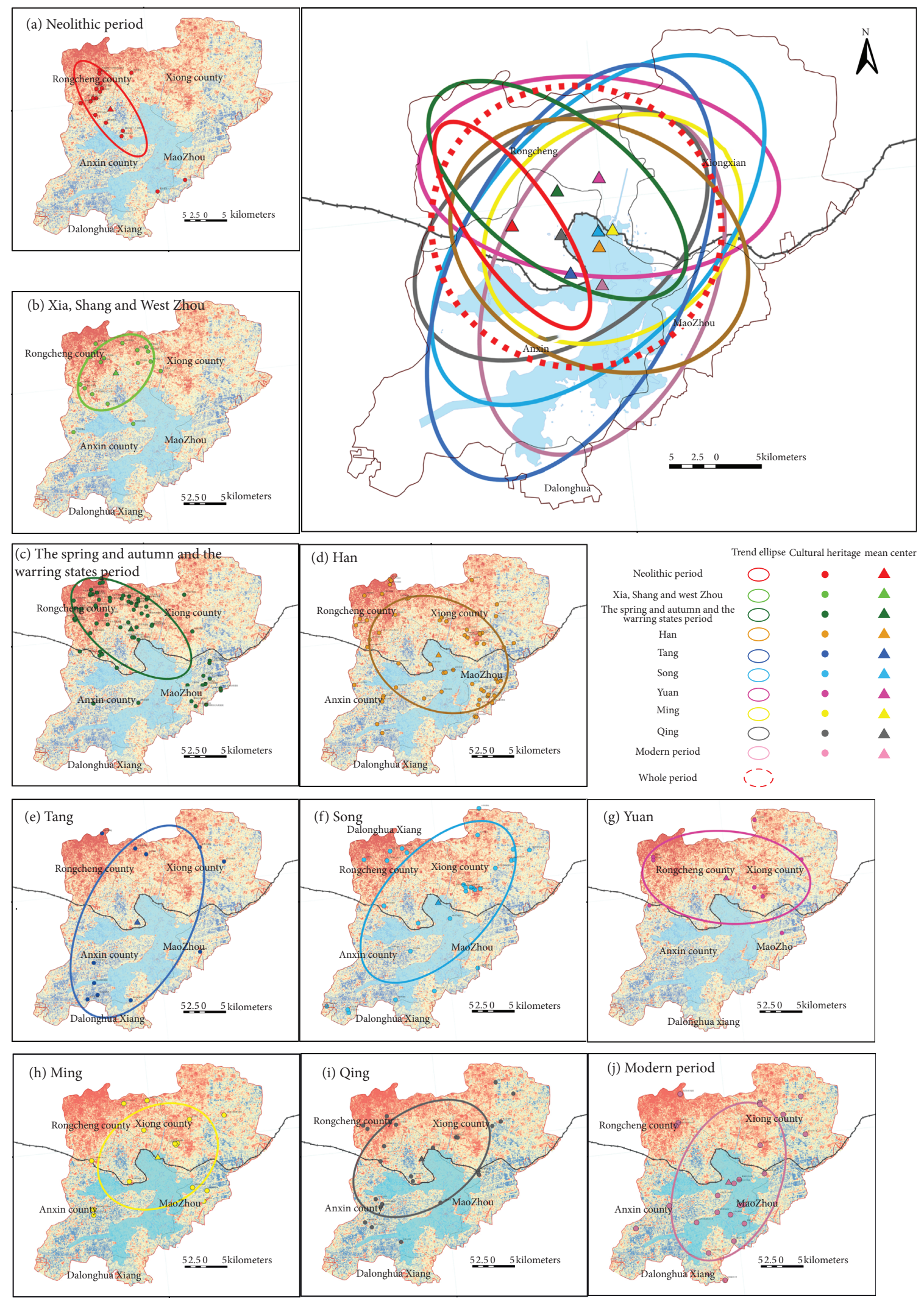

FIgURE 11: Spatiotemporal distribution trend of heritages in different periods. 


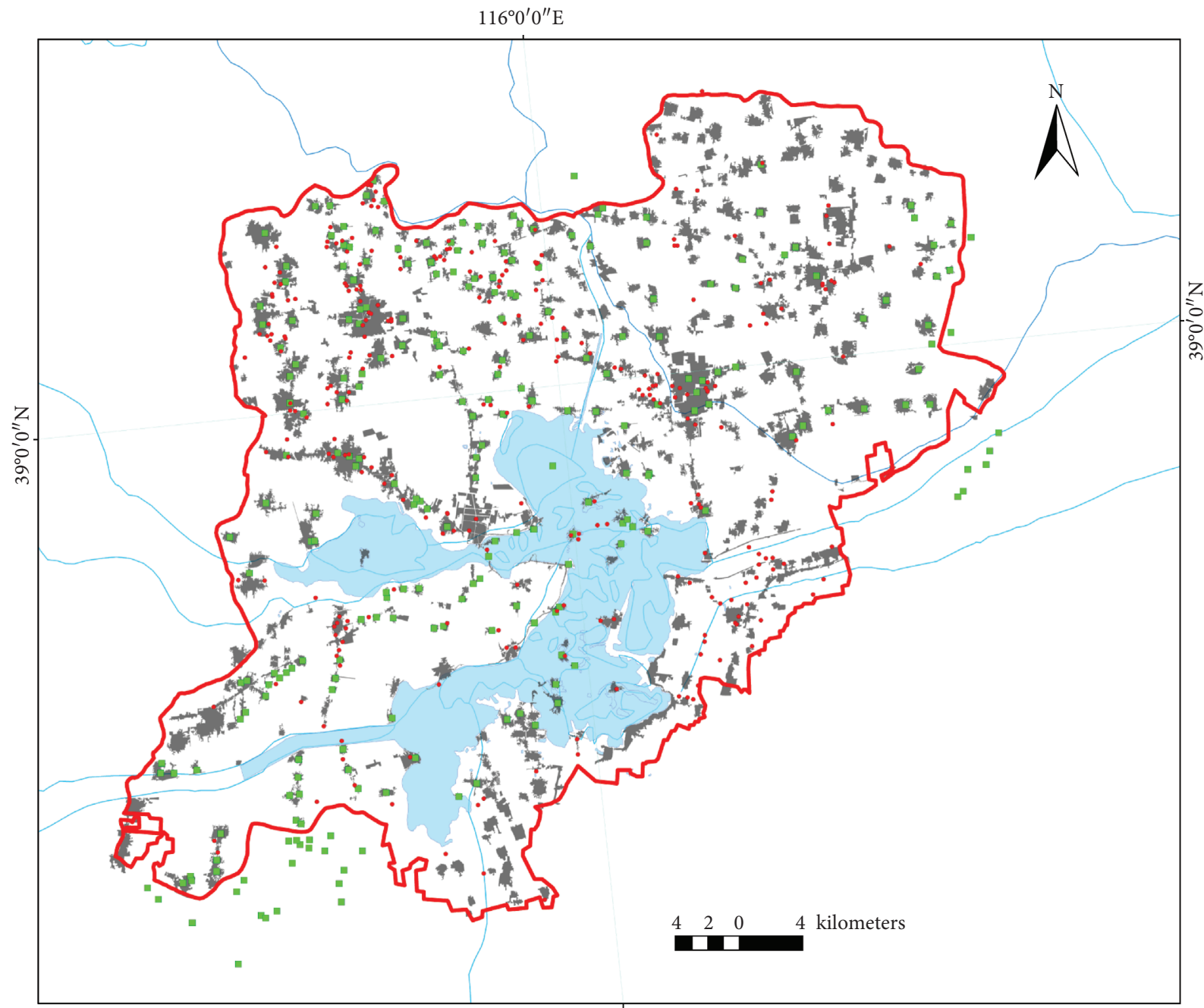

$116^{\circ} 0^{\prime} 0^{\prime \prime} \mathrm{E}$

Scope of xiong'an

- Material cultural heritages

- Qing dynasty settlements
Contour of current settlements Baiyangdian (1996)

Rivers

FIGURE 12: Superposition of material cultural heritages with Qing Dynasty and modern settlements.

with county seats or large towns are within the contours of these high-level localities. The wide dislocation indicates that, with heritages as the center, the settlements that evolved by the first law of geography will not grow homogenously in space. Another interpretation is that the settlements continue to accumulate and cover up most heritages; only those on the edges of the settlements can be found.

3.4. Analysis of Influencing Factors. The necessary conditions (Table 2) and variable combinations (Table 3) were calculated separately by fsQCA. For the outcome variable of SO, PS is the necessary condition, and $\mathrm{LO}, \mathrm{BU}, \mathrm{AR}$, and $\mathrm{CU}$ are the sufficient conditions (Table 2), indicating that SO determines the development of ancient society, while the other single conditions play a weak role. For the outcome variable of $\mathrm{HN}$, there is no necessary condition, and LO is the only sufficient condition. Thus, LO is the top influencing factor of HN. Looking back in
TABLE 2: Necessity of single variable.

\begin{tabular}{lcccc}
\hline \multirow{2}{*}{ Variable } & \multicolumn{2}{c}{ Outcome: SO } & \multicolumn{2}{c}{ Outcome: HN } \\
& Consistency & Coverage & Consistency & Coverage \\
\hline PS & 0.962963 & 0.896552 & 0.766667 & 0.793104 \\
LO & 0.851852 & 0.741935 & 0.866667 & 0.83871 \\
TU & 0.333333 & 0.5625 & 0.4 & 0.75 \\
BU & 0.851852 & 0.958333 & 0.633333 & 0.791667 \\
AR & 0.814815 & 1 & 0.566667 & 0.772727 \\
CU & 0.814815 & 1 & 0.633333 & 0.863636 \\
WA & 0.703704 & 0.703704 & 0.733333 & 0.814815 \\
\hline
\end{tabular}

history, whenever the LO of Xiong'an increased (e.g., East Zhou, Song, and Qing), advanced human activities appeared in the region, forming many high-level heritage carriers. Meanwhile, more low-level derivative heritage carriers emerged in the peripherals. The relatively small impact of PS may be related to the fact that many remains are not recognized as heritages. When the PS is high, the social prosperity and human activities 
Table 3: Antecedent combinations for SO and HN.

\begin{tabular}{|c|c|c|c|c|c|c|}
\hline \multirow{2}{*}{ Variable } & \multicolumn{3}{|c|}{ SO } & \multicolumn{3}{|c|}{$\mathrm{HN}$} \\
\hline & Config. 1 & Config. 2 & Config. 3 & Config. 4 & Config. 5 & Config. 6 \\
\hline PS & 0 & 0 & 0 & 0 & $\bullet$ & $\bullet$ \\
\hline LO & $\bullet$ & & $\bullet$ & & 0 & 0 \\
\hline TU & o & O & $\bullet$ & O & ○ & $\bullet$ \\
\hline BU & $\bullet$ & $\bullet$ & o & O & $\bullet$ & O \\
\hline $\mathrm{AR}$ & $\bullet$ & $\bullet$ & O & O & $\bullet$ & o \\
\hline $\mathrm{CU}$ & $\bullet$ & $\bullet$ & O & O & - & o \\
\hline WA & & $\bullet$ & $\bullet$ & 0 & & $\bullet$ \\
\hline Raw coverage & 0.62963 & 0.518519 & 0.185185 & 0.2 & 0.5 & 0.2 \\
\hline Unique coverage & 0.148148 & 0.037037 & 0.111111 & 0.133333 & 0.433333 & 0.1 \\
\hline Coverage consistency & 1 & 1 & 0.833333 & 0.857143 & 0.882353 & 1 \\
\hline Solution coverage & & 0.777778 & & & 0.766667 & \\
\hline Solution consistency & & 0.954545 & & & 0.884615 & \\
\hline
\end{tabular}

Note. or means the condition exists; $\bigcirc$ or 0 means the condition does not exist; blank means the condition in the combination either exists or does not exist; or $\bigcirc$ means the condition is a core condition; $\bullet$ or $\bigcirc$ means the condition is an auxiliary condition.

could create many remains. However, most of them belong to ordinary people and are unqualified for heritage protection. Taking tombs as example, almost all heritage tombs belong to landlords and those of even higher social classes. These tombs are made with higher grade, better materials, and more exquisite burial items than those of ordinary people.

Further analysis shows that, for the outcome variable of SO, the overall coverage and consistency of the three condition combinations met the judgment criteria for significant conditions. Specifically, Config. 1 and Config. 2 have similar and strong explanatory powers for the outcome. The latter only adds one condition: the large AW. For the outcome variable of $\mathrm{HN}$, the overall coverage and consistency of the three condition combinations also met the criteria. Among them, Config. 5 had a relatively strong explanatory power, the condition combination of Config. 5 is the same as that of Config. 1, and the two combinations are close in consistency. Therefore, SO can be promoted by the combination of high PS, strong LO, low TU, frequent $\mathrm{BU}$, high $\mathrm{AR}$, and rich $\mathrm{CU}$. This condition combination is consistent with our intuition.

To sum up, the consistency of condition combination indicates that a prosperous society is more likely to produce and preserve material cultural heritages. This agrees with the inference about heritage survival from the probability theory [40]: for a region in a certain period, if a social state or cultural behavior is very active, the material carriers will be abundant, and the remains will be more likely to be discovered by the later generations. However, the difference in necessary conditions indicates that the conditional variables differ in importance: $\mathrm{LO}>\mathrm{PS}>\mathrm{WA}>\mathrm{BU}=\mathrm{CU}>\mathrm{AR}$. Based on this ranking, different weights can be assigned to the probability of each kind of potential heritages. In a certain period, if a heritage has a high correlation with the necessity of a factor, it should be assigned the probability weight corresponding to that factor.

\section{Detailed Depiction of Ancient Human Space in Xiong'an}

4.1. Prehistory $(10,000 \mathrm{BC}-2,000 \mathrm{BC})$. In the Paleolithic period ( 3 million $\mathrm{BC}-10,000 \mathrm{BC}$ ), the sites were mainly located in the northern mountains of North China, forming a ring around the Central Hebei Plains. There was no site in the hinterland of the plains. The nearest site to Xiong'an is Beibianqiao site, Laishui County, amidst the east hills of the Taihang Mountains. The remains are primarily the bones of deer and rats. It can be speculated that humans then mainly live in the mountains (Figure 11(a)).

In the early phase of early Neolithic period, a major discovery was made in the northwest Xiong'an at Nanzhuangtou site, Xushui District, Baoding, and at Beifudi site, Yi District, Baoding [27], which marks human entry into the plains before the east of the Taihang Mountains and the gradual shrinkage of the vast water area in Central Hebei Plains.

From the late phase of early Neolithic period to the early phase of Yangshao period (6,500 BC-4,700 BC), discovery of phase 1, Shangpo site, Rongcheng, and the underlying part of Liangzhuang site, Anxin, mark the entry of humans in the scope of Xiong'an. This unveils the human space evolution in the region. The two sites are located on the northern highland of Baiyangdian Lake and the discontinuous highland in the southern low-lying area, respectively. Combined with Nanzhuangtou site, the two sites exhibit a gradual convergence to Baiyangdian Lake in the northwest-southeast direction (Figure 11(a)). The trend is small-scale evidence on the large scale advancement of original heritages in North China from the Taihang Mountains to the southeastern plains. The elevation of Liangzhuang site is merely $7 \mathrm{~m}$, suggesting that Baiyangdian Lake is then a network of lakes, depressions, and highlands, rather than a complete water area. Apart from animal remains, a lot of shells and fish bones are unearthed at these sites. This means humans have moved close to Baiyangdian Lake and made a living out of the lake. With Shangpo site as the center, sites like Gouxi and Beicheng appear in the north, while Beizhuang site appears in the south. The spacing between these sites is about $2 \mathrm{~km}$. The settlements expand along the highland; that is, the primitive humans settled down in Shangpo and gradually reproduced and spread from that place, forming the Shangpo Cluster, Rongcheng. In the meantime, the underlying part of Liucun site appears deep in Baiyangdian 
Lake between Shangpo and Liangzhuang, west to today's downtown Anxin. By spatial distribution, this site is an extended settlement of Shangpo Cluster.

In the early to middle phase of Yangshao period (4,800 BC-3,500 BC), Anxin Cluster, which centers on Liucun, slightly extended eastward, approaching the western shores of Baiyangdian today. In this cluster, the upper part of Liucun site is added above the underlying part. Compared with Shangpo Cluster, Anxin Cluster extended very slightly, as it is in the vicinity of Baiyangdian. During the same phase, Sangezhuang site on the southern shores also approached the lake, indicating the stability of water area and limitation of land area in the study area.

In the late phase of Yangshao period (3,500 BC-3,000 BC), many new sites emerged, including the upper part of Shangpo, the upper part of Gouxi, phase 1 of Wufang, and Dongniu. Anxin Cluster was further enriched and expanded significantly to Baiyangdian on the south.

During the Longshan period (2,600 BC-2,000 BC), several sites, namely, Bailong, Shenmingting, and Laicheng, appeared far to the south of Shangpo Cluster. These sites expanded along the highlands on the outer ring to the west of the southeastern depression (today's May $4^{\text {th }}$ Farm) to Baiyangdian in the south and formed a clear linear correlation with Anxin Cluster. This trend is related to the cultural attraction of early settlements in Anxin [41] and signifies the growing ties with Baiyangdian.

In the Neolithic period, the ancient humans gradually migrated deep into Central Hebei Plains from the peripheral mountains. Along the rivers and lakes, they explored the depressions at the center and established scattered settlements on highlands. The primitive survival strategy is waterloving on the macroscale and water-hating on the microscale. Later, the settlements were expanded into a linear cluster along the C-shaped highland, approaching Baiyangdian in the south. The spatial spacing and development timing showcase the scale of the living space, resource control range, and evolution step length for primitive humans and precisely illustrate the form and shrinking trend of the water area of Baiyangdian.

4.2. Xia, Shang, and West Zhou Dynasties (2,070 BC-771 BC). In Xia and Shang Dynasties, phase 3 of Shangpo and phase 2 of Wufang appear in Shangpo Cluster. As for Anxin Cluster in the south, the sites also witness superposition and extend to the northwest. The northwest-extending part meets the south-expanding part of Shangpo Cluster at Dongxiaoli and phase 1 of Xingkezhuang. As a result, the south cluster grows plumper. In the meantime, the east cluster of the C-shaped highland starts to develop, giving birth to sites like Beizheng and Liangmatai. The cluster expands obviously to the east and merges with Baigou site $13 \mathrm{~km}$ in the northeast. It can be deduced from the above that Shangpo Cluster has evolved into a settlement network expanding from a large and stable core. Besides, the southward movement to water changes to the eastward and westward movements to land (Figure 11(b)). This proves the dominance of agriculture in the social production mode of Central Hebei Plains in Shang
Dynasty [42]. Moreover, the time and spatial densities of new sites are much higher than those of previous ones, indicating that the fast population growth stimulates the expansion of settlement system to a wider scope of land.

Regional records start to appear in this period. At the transition from Xia Dynasty to Shang Dynasty, Yishi, a northern tribe under the rule of Shang, lived in the basin of ancient Yishui River (today's Juma River, a tributary of Daqing River). It can be deduced that Yishi entered the hinterland of Central Hebei Plains near Baiyangdian along the Yishui River from the Taihang Mountains and grew into the Shangpo Cluster. The social production of the tribe shifted from hunting, gathering, fishing, and animal husbandry to agriculture and planting. On a larger scale, the Chinese territory is dotted with civilizations, which expand from their core areas. Crisscrossed by rivers and lakes, the plains of Xiong'an provide a zone of engagement of different civilization circles. Archeological evidence suggests that Shangpo and the nearby areas in Xiong'an have diverse and complex cultural relics, which belong to different cultures. Xiong'an is a whirlpool, where cultures from all directions merge and intermingle, including the underlying part of Xiajiadian from the north, Yueshi from the east, Xia and Shang from the south, and Baiyan from Central Shanxi of the west.

4.3. The Spring and Autumn and the Warring States Period $(770 B C-221 B C)$. In the Spring and Autumn and the Warring States Period, there was a significant growth of heritages in the west, north, and east sides of Shangpo Cluster. In particular, the number of heritages rockets up in the east part of the C-shaped highland. In the middle of that part, Nanyang site develops into the core of a new dense group, which spreads as far as Xingcun site in the west (within today's downtown Xiongxian). Xingcun site is the first beacon of human activities in Xiongxian and a sign of the initialization of the belt settlement system in the east part of the C-shaped highland. In the south, Anxin Cluster has only two additional heritages: Xidi tomb group and Beiliuzhuang site. The two new heritages approximate the northern shores of today's Baiyangdian. The latter even lies within the water area today. Therefore, this part of water area in Baiyangdian is very similar to that nowadays. On the other side of the lake, a dense group of heritages appear in Mozhou. The overall distribution trend seems to be related to the Rongcheng-Xiongxian settlement belt (Figure 11(c)).

In this period, Yan State builds the Southern Great Wall across the hinterland of Xiong'an [43]. The relevant sites agree well with the northern shore of today's Baiyangdian. Only the north end is partly within the water area. Hence, the lake is of similar form to that of today. The relationship between cities and lakes also reflects the fact that the construction principle of early Great Wall is correlated with the mode of city construction: digging trenches in the ground and piling up the excavated soil into walls. Historical documents testify that many of the isolated lakes along the south of the Great Wall are manually connected into a continuous barrier. It is the first attempt of mass transformation of nature for the purpose of defense. 
Taking the Great Wall as the division line, except Mozhou, the heritages are rich and balanced in the north and scattered and few in the south. Considering the scale of each heritage, Nanyang site, which lies at the core of the east settlement belt, is huge in size and contains high-level ritual vessels. It is speculated by some to be the midterm capital of Yan State, Linyi. According to historical record, Yan State built three cities to guard itself against Zhao State, namely, Hunni (today's Anxin), Santai (today's Santai Town), and Gecheng (today's Anzhou Town, later occupied by Zhao). Gecheng is outside the Great Wall, while the other two cities are close to the inside of the wall. The three cities form a triangle centering on the western tip of today's Baiyangdian and protect the large opening of the lake to the southwest. This opening faces Nanyang site deep in Xiong'an from afar. The heavy defense and the abundant heritages in the north of the wall bear witness to the high social and political statuses of Nanyang, which promote the rapid development of regional settlements and culture.

The low presence of heritages in the south of the Great Wall is attributed to the low level of cultural development, since the region is a low-lying lake and swamp frontier far away from the center of Zhao State. The high density of heritages in Mozhou comes from the fact that the city originally belongs to Yan (later occupied by Zhao). The development of this city is backed up by the prosperous settlement system of Yan State. In addition, the flourish of settlements in Mozhou is supported by its critical geographical location: the roads from all directions converge in the city, the neck of the narrow wetland corridor. The city is a magnet to merchants and a strategic place during the wars. In the Warring States Period, the study area changed from centripetal growth to the confrontation state for the first time, and the local man-earth relationship shifted from water-loving to passive water-hating. Due to the confrontation between Yan and Zhao, the pure natural barrier of Baiyangdian was reinforced into the boundary of cultural cognition. Since then, the lake has been treated as administrative boundaries on different scales.

4.4. Han Dynasty (206 BC-220). In Han Dynasty, under the background of grand unification, the heritages break through the imbalanced development fueled by the polarity difference between north and south of the Yan Great Walls. The heritage distribution is more homogenous and extensive than ever before, and the scale of cultural space increases prominently. The traditional gathering place of heritages in the northern highland remains prosperous. In addition, a lot of heritages appear around and even in Baiyangdian, which used to have little heritages. In the northeast, the Rongcheng-Xiongxian (east) cultural belt has an abundance of heritages, primarily on the east and west of the seat for Zhuojun prefecture of Han Dynasty (today's Guxian Village) and Yiyi of Yan State. Meanwhile, the eastern node of the east belt, i.e., Xiongxian, sees further increase of heritages. In the southeast, Mozhou still boasts a high density of heritages, most of which are tombs. Thus, the city remains prosperous in this period. In the southwest, the area of today's Anzhou has three tombs and heritages, the result of the old Anzhou city being built in Han Dynasty. Deep in Baiyangdian, multiple sites, e.g., Dazhangzhuang, Dongdiantou, and Wangjiazhai, emerge, indicating that the lake keeps a low water level in Han Dynasty (comparable to the water level in dry season of 1992). The places of the above new sites are all key nodes in the settlement system of Xiong'an today. Since Han Dynasty, the cultural space and settlement system in the study area has been basically stable.

The material cultural heritages of Han Dynasty clearly fall into two categories: settlements and tombs. There are many tombs (31) in this period, accounting for $53.4 \%$ of all heritages. On the macroscale, the two types of heritages cluster separately and only overlap in local areas. On the microscale, settlements and tombs mutually repel each other; the mean spacing between settlements and tombs is about $500 \mathrm{~m}$. Further, the tombs are all away from or on the edges of the early and modern settlements (Figure 11(d)). These laws are similar to the distribution pattern of Han Dynasty tombs around Xiong'an: the density and level of Han Dynasty tombs in Mancheng in the west are much higher than those in other places. Relevant studies confirm the spatial differentiation of settlements and tombs in Han Dynasty; Han Dynasty tombs have nurtured special spatial attributes. Furthermore, the wide distribution of numerous settlement sites and high-level tombs is microscale evidence on the then macro policy of the state: In Han Dynasty, Zhuojun prefecture was densely populated. The enfeoffment policies in the late phase of that dynasty bred many small landlords, who competed to stake claims to unowned land [44]. This coincided with the shrinkage of Baiyangdian. As a result, humans advanced into the receding water area to obtain more land from the hinterland of Baiyangdian.

4.5. Tang Dynasty (618-907). In Tang Dynasty, there were relatively few material cultural heritages. The few heritages can be categorized into two distinctive groups. The northern group was scattered on the northern boundary of Xiong'an. The southern group gathered in the nontraditional cultural gathering space in the southeast corner and tended to connect with Anzhou in the north. The traditional cultural gathering space in the hinterland was completely blank. The heritages are either sites or tombs, including one site and one tomb of Buddhist carved stones (Figure 11(e)).

In this period, the social, economic, and cultural development in Hebei can be roughly split into two phases by the An Lushan Rebellion. In the previous phase, the study area flourished in agriculture, planting, and animal husbandry, under the favorable policies from the central government. It is recorded that Mozhou had 99 lakes. Although the number is fictitious, it is greater than that that in any other age. At that time, the area must have had numerous large and interconnected lakes. The government diverted water to irrigate farmlands in the east, creating more than 200 hectares of new arable fields. As late as the reign of Emperor Xuanzong, the study area still constructed water conservancy projects and expanded farmlands. Therefore, 
the heritages in the study area ought to have developed towards Baiyangdian and survived to this day. However, this is not the case in reality. Hebei was the main battleground during the An Lushan Rebellion. The residents fled in masses, and the social economy was wrecked [45]. The administrative regions were also adjusted. Two regional centers formed in this phase: The southern part is located in Mozhou further in the south, with Anzhou Town (today's Gezhou, and Xingxian in Tang Dynasty) as the center. The northern part is located in Yizhou in the north, with Rongcheng (Youxian, Quanzhong County, etc.) as the center. Therefore, the polarized distribution of heritages coincides with the centroids of local spaces. Despite the vagueness of spatial semantics, it can be said that the heritage distribution of Tang Dynasty has something to do with the social situation in the late phase. Finally, Buddhist carved stones were discovered for the first time in the study area, taking up quite a portion in the local heritages. This reflects the boom of Buddhism in Tang Dynasty [46]. One of the Buddhist carved stones is found in Mozhou, which has profound links with Buddhism.

4.6. Song Dynasty (960-1127) and Liao Dynasty (907-1125). During the Song Dynasty, material cultural heritages were widely distributed, yet primarily along the southern shores and northern margin of Baiyangdian. In the south, Xiongxian Cluster witnesses extra remarkable heritage development, involving sites like Beiying and Aixilou and tunnels on Song-Liao borders. On the northeastern margin of that cluster, multiple sites appear in a string, including Qigang tunnels and tombs. If the two places are connected by a line (about $45^{\circ}$ ), which extends to the southwest across Baiyangdian in the southwest corner of Xiong'an, then the southern part is rich in sites, which are uniformly scattered along the shores of the lake. This feature is demonstrated by the previous ellipses (Figure 11(f)). The northern part has relatively few sites, which concentrate on the corner $4 \mathrm{~km}$ in the northwest of Rongcheng. The traditional gathering area in the south and east of Rongcheng is virtually blank. In Anxin, several heritages are available in today's Anzhou only, signifying the origin of the ancient city of Anzhou in northern Song Dynasty.

In this period, Xiong'an was situated exactly on the boundary between Song and Liao [47]. The strategic Waqiao Pass was within the seat of Xiongxian. It is when the name of Xiongzhou became famous across the county. Early on, the two sides were in a stalemate. Since the horsemen of Liao could move rapidly across the vast plains, the Song army built up a $400 \mathrm{~km}$-long Great Wall on the Water in a few years, the largest water defense work in the region. Roughly at the same time, an Underground Great Wall of tunnels was established from Xiongxian to Bazhou. The two "Great Walls" complement each other, forming a complex stereo defense system. The heritage distribution in the south of the said connecting line is highly consistent with the defense system.

In 1005, Song and Liao signed a peace treaty, unveiling a century of peace [48]. Then, the study area was coadministered by the two parties. To facilitate trade and exchanges, four market towns were set up in Xiongzhou (today's Xiongxian), Bazhou, Anshu Military Town (today's Xushui), and Guangxin Military Town (northwest of Baoding). Xiongzhou was the largest among the four. In this way, Xiongzhou was transformed from a fortress on the frontier into a stage for cross border trade and ethnic fusion. The traces of cultural prosperity can be found even today. Many place names retain the character "wu" (literally "affair"), a symbol of trade function back then. For example, Mijiawu and Matouwu mean the affairs of grain and horse trades, respectively. The trade greatly promoted the development of settlement system in Xiongzhou. By contrast, the previous leader, Rongcheng Cluster, met a major setback. At that time, Rongcheng County was split into different parts. Liao designated a new Rongcheng on the north of Juma River, while Song relocated the county to Xiongzhou. That is why no heritage is found in the southern part of Rongcheng.

4.7. Yuan Dynasty (1271-1368). In Yuan Dynasty, there were only eight material cultural heritages. The distribution of them is rather unique. The traditional gathering place of culture in the northern highland is blank. Only three heritages appear on the line from Xiongxian to Mozhou in the southeast corner. The other five heritages are scattered on the peripherals of Xiong'an. For instance, the Tombstone of Duke Liang and Longci Ganying Inscription appear on the far end of the western outskirts of Rongcheng; Banzhuangtou and Donghegang tomb groups are the only heritages in and to the northeast of Xiongxian; Anxin in the south has no heritage.

During the transition from Jin Dynasty to Yuan Dynasty, the two sides fought fiercely in Hebei. Many residents were massacred. The massacre, coupled with the fleeing from war and the southward relocation of Jin military households, led to a more than $90 \%$ drop in regional population. The wars also forced wealthy and influential Han families in Hebei to stockade their villages. The common people looking for shelter became serfs. Therefore, the social order, production relationship, economy, and culture retrograde caused the significant decline in material cultural heritages. Considering the northward shift of ellipse center and the reduced scale of the ellipse (Figure 11(g)), it can be seen that Xiong'an, especially the peripherals of Baiyangdian, had a low activity of society and culture. Judging by attributes, inscriptions and sites make up the most of heritages. This is a typical feature of Yuan Dynasty: Due to the lack of surviving texts, inscriptions become the main basis for research. The contents of the inscriptions are mostly about the Mongolian rulers [49]. For example, the Tombstone of Duke Liang reports the rewards given to the military in Hebei [50]. The linear distribution of sites from Xiongxian to Mozhou holds evidence of the prominence of this channel. Historical records show that Xiongxian had a large number of temples in Yuan Dynasty. The Grand Temple of Mozhou, a provincial heritage now, was built in this period, attracting worshippers till this day. The above verifies the importance of the line from Xiongxian to Mozhou. 
4.8. Ming Dynasty (1368-1644). In Ming Dynasty, the heritages concentrated in the hinterland and moved back to the traditional gathering places. The notable heritages include Yuan Chonghuan Tomb and Hongxilou site near Xiongxian Cluster, the ancient walls of Anzhou, and the Inscription of Temple Construction in Mozhou. The other heritages are scattered across the study area. The number of heritages is greater than that in Yuan Dynasty. Compared with Qing Dynasty, Ming Dynasty has relatively few and low-diversity material cultural heritages, although the two unified dynasties are similar in production state and level of culture development and close in time (Figure 11(h)).

At the beginning of this period, Hebei was sparsely populated. The central government relocated many people there from other places. During the Jingnan Campaign, especially the Baigouhe Battle, the regional culture was destroyed from the root, and most residents were killed or forced to flee [51]. After the reign of Emperor Yongle, almost every village was newly built by immigrants. Therefore, the human background is rather weak in the study area. When it comes to the early phase of Emperor Hongzhi, Baiyangdian was silted heavily after consecutive droughts, which attracted settlement development towards the lake area. The lakebed was turned into farmlands, and the central part was even used as a ranch. After that phase, huge changes took place in the environment. Baiyangdian began to grow into a boundless lake. The expansion of water area in the late phase checked and balanced the inward development of settlements in the early phase, such that several heritages appear to approach the lake from different directions.

In addition, the heritages are further differentiated into Buddhist sites, tombs of prominent personage, and city walls. Because the time is close to now, the heritages reflect the details of the then culture. Since the founder of Ming Dynasty used to be a monk, Buddhism is included in the national governance system. Temples spring up across China [52]. This explains why Ming Dynasty has more Buddhist heritages than any other period. The coexistence of Buddhist heritages and city sites holds testimony to the official recognition of the religion. The well-preserved tombs belong to officials known for their righteousness and frankness, two attributes hailed in the popular Neo-Confucianism of that dynasty. The two sites of city walls directly mirror the national policy of "building high walls."

4.9. Qing Dynasty (1636-1912). In Qing Dynasty, material cultural heritages existed broadly in Xiong'an. The high density areas were well correlated with the traditional gathering space and corresponded to the high-level nodes in today's settlement system. Anxin boasted half of all heritages in Xiong'an, way more than the other two counties. Gathering around Baiyangdian, the heritages have a large scale of spatial distribution and belong to various types, including Zhaobeikou Opera House, Sage Hall Pavilion, and Inscription of Royal Appointment of Tianzeng. The heritages of Rongcheng are crowded in a narrow range near today's downtown Rongcheng. The small scale of distribution involves Guandi Temple and Chenghuang Temple. Xiongxian sees discretized distribution of heritages, such as Xihuai Mosque and Chen Zizheng Tomb. The heritages in the latter two counties are mostly about local affairs and culture (Figure 11(i)).

In this period, the country was unified, and Xiong'an received much attention for its strategic location (near the capital) and natural endowments. At the beginning of Qing Dynasty, Baiyangdian was often flooded. Since it lied close to Beijing, the government spent much efforts to control the floods. The abundant water nurtured a beautiful landscape. The traditional eight sceneries of Xin'an, Rongcheng, and Xiongzhou contained a lot of water elements, attracting many senior officials. Thanks to the continuous improvements by Emperors Kangxi and Qianlong, Baiyangdian became a royal retreat of beautiful scenery, advanced farming and fishing, and excellent hunting ground. It is often compared to Mulan Paddock in the northern province of Rehe [53]. As a result, the cultural development of the lake was pushed to a climax. Four palaces were constructed around the main lake at the best scenic lookouts in the four directions, which delineated the core scenic area. The locations of the four palaces are significantly correlated with today's heritages, such as Zhaobeikou Opera House, Duncun Concert Hall (intangible cultural heritage), and stone remains of the palace in Juantou Village. On a larger scale, Baiyangdian palaces were part of the temporary imperial palace system across the country at that time and thus closely bound with royal power. The improvement of the location importance of Anxin directly promoted the cultural development in the surroundings of the lake (Anxin) over that of Rongcheng and Xiongxian.

In this period, the differentiation of material cultural heritages is even more clear. Different types of heritages carry richer and more refined information, involving almost every aspect, ranging from customs and religious beliefs to economic production. The balanced distribution demonstrates the sound social and cultural form in Qing Dynasty. Of course, this is partly attributed to the fact that the heritages are well preserved due to the short history. Further investigation shows that the material cultural heritages have rich and vivid local features, which increase from Baiyangdian to the peripherals. The heritages surrounding the lake seem to imply the social attributes of high levels, different from local attributes. Combined with legends, concerts, and dancing [54], the sense of high-level social attributes is evident, with an air of solemnity and magnificence. This is obviously the result of the intervention of royal culture into space.

4.10. War of Resistance and War of Liberation (1931-1945). During the Wars of Resistance and Liberation, the heritages in the study area mainly included martyrs cemeteries, cenotaphs, and war sites. They can be basically divided into two types: urban monuments marking the collective memory of a specific time and space, e.g., Rongcheng Martyrs Cemetery; historical event markers 
with clear spatiotemporal information, e.g., the site where Yanling Team ambushed Japanese army and Mijiawu Martyrs Cemetery. The latter type of heritages is located on the peripherals of main settlements back then and highly correlated with natural barriers (reed marshes) and artificial barriers (tunnels) (Figure 11(j)). The distribution shows how Chinese and Japanese armies were located and interacted in that period. At that time, Central Hebei Plains was occupied by the Japanese. The flat and bare terrain posed a severe challenge to the Chinese army. Interlaced by rivers and ditches and overshadowed by reed marshes, Baiyangdian provided the most reliable natural barrier for the Chinese army. The military and civilian therefore established a base area in the lake and launched guerrilla warfare against the Japanese. Mijiawu and other villages, which have fewer reed marshes around, resorted to the more extreme tunnel warfare. The tunnels in Mijiawu almost overlap with the tunnels on Song-Liao borders, a sign of direct inheritance of cultural behaviors. The above confrontation mode was formed through the innovative utilization and development of heterogenous environment against a homogenous background. The spatiotemporal attributes of Baiyangdian were transformed into the confrontational features of shielding and defense on the plains.

\section{Prediction and Conclusions}

In the probability distribution map of heritages (Figure 13), the extremely high area of heritage density appears at the center and two ends of the C-shaped high density belt, as well as places like Xiongxian, Anzhou, Mozhou, and Zangang. After the map is superimposed on the scope of planned construction for Xiong'an, the startup area of Xiong'an belongs to the central to southern part of the northern highland of Baiyangdian, just outside the extremely high area of heritage density. However, the startup area overlaps the high area of heritage density in many places.

(1) The eastern part of the startup area overlaps the medium association area extending from the extremely high area of Xiongxian. The important Anyang site and its influencing scope precisely are located in this area.

(2) The northwestern tip of the startup area overlaps the turning point of the south part in the $\mathrm{C}$-shaped high density area, showing a high distribution probability of potential heritages.

(3) The southwestern belt and its nodes along Anxin of the startup area coincide with the south part in the $\mathrm{C}$-shaped high density area and closely intertwine with the buffer zone of the Southern Great Wall built by Yan State. About one-third of the central part of the planned area falls on low probability zones and even blank zones, which favors the construction of Xiong'an. However, the startup area lies slightly to the east of this area and partly overlaps the medium area of the probability.

During future construction activities, archeologists should focus on the above three overlap areas, where surface or underground material cultural heritages potentially exist. The constructors of the startup area must fully consider the influence of the cultural sphere related to Nanyang site from the northeast. Besides, the peripheral extension area of the startup area overlaps the high and extremely high density areas in many places, such as Guigang, downtown Xiongxian, downtown Anxin, and Rongcheng and its east and west. All of them used to be medium and large urban settlements. It is very likely that heritages are discovered in these places. Before construction, geological surveys must be carried out in such places. Further away from the startup area, the special small towns will be built on the original sites. They partly overlap the high value areas (e.g., Anzhou) and a few low and medium value areas. The local governments should carefully arrange preliminary surveys, especially if the new towns are relocated or deviate from the original sites. However, the probability of discovering new heritages in these places is low, because of the small envelope area for prediction.

Guided by material cultural heritages, this paper makes a detailed depiction of the pattern and features of the human space in Xiong'an in different stages of history. It was learned that, on the vast North China Plains, the social and human activities of Xiong'an were greatly affected by complex social, political, and cultural factors. The influence is centered on the heterogenous element of Baiyangdian. On the macroscale, these factors are consistent in the influence of social development and heritage survival. On the microscale, there are sequence and type differences between the different conditions on heritage survival. Based on the spatial distribution of existing heritages, the authors dew a prediction map for the probability of potential material cultural heritages in Xiong'an. As Xiong'an is set to launch a massive construction campaign, our research results will provide forward-looking guidance for urban planning, urban design, and material cultural heritage protection. Of course, this research mainly concentrates on the macro level. In future, the authors will resort to techniques like the far infrared mapping with unmanned aerial vehicles and ground penetrating radar to make more accurate prediction of potential heritages in key blocks, including the first batch of planned construction areas and the areas with a high probability of heritage existence. 


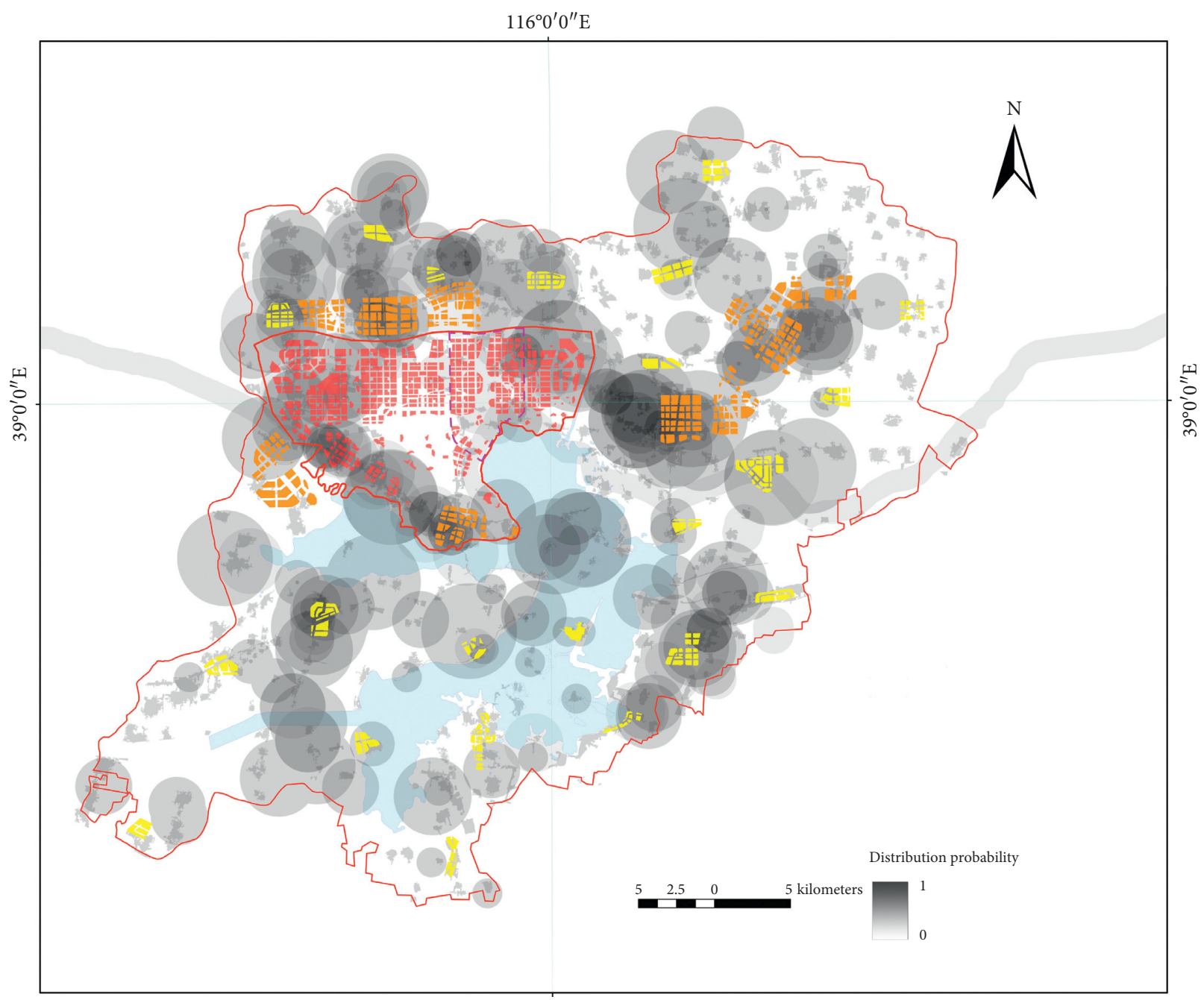

$116^{\circ} 0^{\prime} 0^{\prime \prime} \mathrm{E}$

\begin{tabular}{ll}
$\square$ & Scope of Xiong'an \\
$\square$ & Startup area \\
\hdashline--- & Initial area \\
$\square$ & Construction land in initial area
\end{tabular}

HIIt Peripheral expansion area

개표 Gathering area

Water area in 1996

FIGURE 13: Superposition between planned construction land and probability distribution of material cultural heritages (the planning map of the startup area of Xiong'an was plotted according to the data from http://www.metaobao.cn/image/1168984132/).

\section{Data Availability}

The data used to support the findings of this study are available from the corresponding author upon request.

\section{Conflicts of Interest}

The authors declare that they have no conflicts of interest.

\section{Acknowledgments}

This work was supported by the Natural Science Foundation of Hebei Province of China (Grant no. E2019201230).

\section{References}

[1] Xiong'an China, “Authorized release: the CPC central committee and the state council decide to establish Xiong'an new area in Hebei province," 2017, http://xiongan.gov.cn/2017-04/ 01/c_129769132.htm.

[2] Y. Zou and W. Zhao, "Making a new area in Xiong'an: incentives and challenges of China's "millennium plan," Geoforum, vol. 88, pp. 45-48, 2018.

[3] Q. Yuan, X. Luo, and J. Li, "A comparative study on agglomeration effects of the central cities of three urban agglomerations in China-a case study of producer services," Advances in Intelligent Systems and Computing, vol. 686, pp. 664-668, 2018. 
[4] S. Yan, J. Yin, Z. Yuan, D. H. Yan, and Y. Yuan, "Research on drought retrieve in Baiyangdian basin, China," IOP Conference Series Earth and Environmental Science, vol. 525, Article ID 012004, 2020.

[5] H. N. Wang, X. Z. Lv, and M. Y. Zhang, "Sensitivity and attribution analysis based on the Budyko hypothesis for streamflow change in the Baiyangdian catchment, China," Ecological Indicators, vol. 121, no. 10, Article ID 107221, 2021.

[6] Y. Yim, Z. G. Niu, and Z. Q. Niu, "Preliminary study on wetland connectivity in Baiyangdian basin," Acta Ecologica Sinica, vol. 39, pp. 1-11, 2019.

[7] C. Wu, Q. H. Xu, Y. H. Ma, and X. Q. Zhang, "Palaeochannels on the north China plain: palaeoriver geomorphology," Geomorphology, vol. 18, pp. 37-45, 1996.

[8] H. C. Wang, "Expansion and contraction of the Baiyangdian lake since 10,000 years ago," Geographical Research, vol. 2, no. 3, pp. 8-18, 1983.

[9] Y. Li, L. Wang, H. Zheng et al., "Evolution characteristics for water eco-environment of Baiyangdian lake with $3 \mathrm{~s}$ technologies in the past 60 years," Computer and Computing Technologies in Agriculture V, Springer, Berlin, Germany, pp. 434-460, 2012.

[10] H. Zhao, "Developing xiongan new area as a sustainable city," in Analysis of the Development of Beijing, Beijing Academy of Social Sciences, Ed., Palgrave Macmillan, Singapore, 2021.

[11] F. Liu and Z. X. Zhang, "Urban expansion in Xiong'an new area since 1975," Geocarto International, vol. 34, no. 12, pp. 1-32, 2018.

[12] F. Q. Niu, "Simulating the sustainability of Xiong'an new area undertaking the industrial transfer from Beijing," Hindawi Complexity, vol. 2021, Article ID 9927397, 10 pages, 2021.

[13] M. Yang, J. G. Gong, Y. Zhao et al., "Landscape pattern evolution processes of wetlands and their driving factors in the Xiong'an new area of China," International Journal of Environmental Research and Public Health, vol. 18, no. 9, p. 4403, 2021.

[14] R. Ma, L. Li, and B. Zhang, "Impact assessment of anthropogenic activities on the ecological systems in the Xiong'an new area in the north China plain," Integrated Environmental Assessment and Management, vol. 17, no. 4, pp. 866-876, 2021.

[15] Hebei Culture Relics Bureau, China, "CCTV: cultural relics protection in Xiong'an new district has achieved phased results, and 44 cultural relics have been found," 2017, http://wenwu. hebei.gov.cn/staticPath/site001_html/\%E5\%AA\%92\%E4\%BD\% 93\%E6\%8A\%A5\%E9\%81\%93/20170815/000001.html.

[16] Y. Yuan, "Cultural evolution and spatial-temporal distribution of archaeological sites from 9.5-2.3 ka BP in the Yan-Liao region, China," Journal of Geographical Sciences, vol. 29, no. 3, pp. 449-464, 2019.

[17] J. Yang, H. Shao, and L. Pan, “The emergence and expansion of Bronzes in the northern zone of China," The Metal Road of the Eastern Eurasian Steppe, Springer, Berlin, Germany, pp. 133-226, 2020.

[18] A. Pei, "The clustering pattern of settlements in the lower reaches of the Yellow river in the late neolithic age," A Study of Prehistoric Settlement Patterns in China, Springer, Berlin, Germany, pp. 283-351, 2020.

[19] W. K. Härdle and L. Simar, "Canonical correlation analysis," Applied Multivariate Statistical Analysis, Springer, Berlin, Germany, pp. 443-454, 2015.

[20] T. Cleff, "Regression analysis," Applied Statistics and Multivariate Data Analysis for Business and Economics, Springer, Berlin, Germany, pp. 353-387, 2019.
[21] J. C. Wang and X. Q. Wang, "Structural equation models," in Structural Equation Modeling: Applications Using Mplus, John Wiley \& Sons, Inc., Hoboken, NJ, USA, 2nd edition, 2019.

[22] B. Rihoux and C. Ragin, "Configurational comparative methods: qualitative comparative analysis (QCA) and related techniques," Configurational Comparative Methods, Sage, Thousand Oaks, CA, USA, 2009.

[23] Y. Liu, J. Mezei, V. Kostakos, and H. Li, “Applying configurational analysis to IS behavioural research: a methodological alternative for modelling combinatorial complexities," Information Systems Journal, vol. 27, no. 1, pp. 59-89, 2017.

[24] F. M. Reichert, N. Torugsa, P. A. Zawislak, and A. Arundel, "Exploring innovation success recipes in low-technology firms using fuzzy-set QCA," Journal of Business Research, vol. 69, no. 11, pp. 5437-5441, 2016.

[25] M. C. Backhans, S. Mosedale, D. Bruce, M. Whitehead, and B. Burström, "What is the impact of flexicurity on the chances of entry into employment for people with low education and activity limitations due to health problems? A comparison of 21 European countries using qualitative comparative analysis (QCA)," BMC Public Health, vol. 16, no. 1, pp. 1-15, 2016.

[26] B. Vis, "The comparative advantages of FsQCA and regression analysis for moderately large-N analyses," Sociological Methods \& Research, vol. 41, no. 1, pp. 168-198, 2012.

[27] National Cultural Heritage Administration, Atlas of Chinese Cultural Relics Hebei Volume (Three Volumes), Cultural Relics Publishing House, Beijing, China, 2013.

[28] D. Berg-Schlosser, G. De Meur, B. Rihoux, and C. C. Ragin, "Qualitative comparative analysis (QCA) as an approach," Configurational Comparative Methods: Qualitative Comparative Analysis (QCA) and Related Techniques, vol. 1, pp. 1-18, 2009.

[29] C. Ragin, "Qualitative comparative analysis using fuzzy sets (FsQCA)," Configurational Comparative Methods: Qualitative Comparative Analysis (QCA) and Related Techniques, vol. 51, pp. 87-122, 2009.

[30] J. Gerring, "Fuzzy-set social science," Studies in Comparative International Development, vol. 36, no. 2, pp. 111-113, 2001.

[31] C. Ragin, Redesigning Social Inquiry, University of Chicago Press, Chicago, IL, USA, 2009.

[32] C. C. Ragin, "Set relations in social research: evaluating their consistency and coverage," Political Analysis, vol. 14, no. 3, pp. 291-310, 2006.

[33] J. Kirchherr, K. J. Charles, and M. J. Walton, "Multi-causal pathways of public opposition to dam projects in Asia: a fuzzy set qualitative comparative analysis (FsQCA)," Global Environmental Change, vol. 41, pp. 33-45, 2016.

[34] K. Domdouzis, P. Lake, and P. Crowther, "GIS databases," in Concise Guide to Databases. Undergraduate Topics in Computer Science, Springer, Cham, Switzerland, 2021.

[35] L. Peter, "Spatio-temporal interpolation: kriging," in Monitoring Continuous Phenomena, P. Lorkowski, Ed., pp. 37-50, CRC Press, Boca Raton, FL, USA, 2021.

[36] Z. Wang, J. Xu, C. Fang, L. Xu, and Y. Qi, "The study on county accessibility in China: characteristics and effects on population agglomeration," Journal of Geographical Sciences, vol. 21, no. 1, pp. 18-34, 2011.

[37] A. Pei, "The clustering pattern of settlements in the middle neolithic age," A Study of Prehistoric Settlement Patterns in China, Springer, Berlin, Germany, pp. 45-95, 2020.

[38] B. J. Wang, S. Bin, and H. I. Inyang, "GIS-based quantitative analysis of orientation anisotropy of contaminant barrier particles using standard deviational ellipse," Soil and Sediment 
Contamination: An International Journal, vol. 17, no. 4, pp. 437-447, 2008.

[39] P. Lake and P. Crowther, "Concise guide to databases," A History of Databases, Springer, Berlin, Germany, 2013.

[40] J. H. Luscombe, "Probability theory," in Statistical Mechanics, J. H. Luscombe, Ed., Taylor \& Francis Group, London, UK, pp. 57-82, 2021.

[41] J. He, GIS-based Cultural Route Heritage Authenticity Analysis and Conservation Support in Cost-Surface and Visibility Study Approaches, The Chinese University of Hong Kong, Shatin, Hong Kong, 2008.

[42] W. Luo, J. Li, Y. Yang et al., "Evidence for crop structure from phytoliths at the dongzhao site on the central plains of China from Xinzhai to Erligang periods," Journal of Archaeological Science: Reports, vol. 17, pp. 852-859, 2018.

[43] Y. Sun, "Bronzes, mortuary practice and political strategies of the Yan during the early Western Zhou period," Antiquity, vol. 77, no. 298, pp. 761-770, 2003.

[44] F. Wang, The "Land Quota" System in the Han Dynasty and its Historical Influence, Routledge, London, UK, 2019.

[45] G. W. Wang, "Reviewed work: the Cambridge history of China by denis twitchett," Pacific Affairs, vol. 53, no. 4, pp. 726-728, 1980.

[46] T. Sata, "The popular Buddhism in the tang dynasty," Journal of Indian and Buddhist Studies (Indogaku Bukkyogaku Kenkyu), vol. 7, no. 1, pp. 127-130, 1958.

[47] P. Lorge, "The great ditch of China and the Song-Liao border," Battlefronts Real and Imagined, Springer, Berlin, Germany, pp. 59-74, 2008.

[48] Y. K. Wang, "The irrelevance of Confucian culture in Chinese military policy: Song-Liao war and peace (960-1005)," The Chinese Journal of International Politics, vol. 2, no. 4, pp. 489-538, 2009.

[49] T. Iiyama, "Genealogical steles in north China during the Jin and Yuan dynasties," International Journal of Asian Studies, vol. 13, no. 2, pp. 151-196, 2016.

[50] T. Iiyama, "Steles and status: evidence for the emergence of a new elite in Yuan north China," Journal of Chinese History, vol. 1, no. 1, pp. 1-24, 2016.

[51] D. C. Twitchett, The Cambridge History of China, vol. 8, Cambridge University Press, Cambridge, UK.

[52] W. X. Ding, "Zhu Xi's choice, historical criticism and influence-an analysis of Zhu Xi's relationship with Confucianism and Buddhism," Frontiers of Philosophy in China, vol. 6, pp. 521-548, 2011.

[53] L. B. Xiao, X. Q. Fang, and Y. J. Zhang, "Climatic impacts on the rise and decline of "Mulan Qiuxian" and "Chengde Bishu" in north China, 1683-1820," Journal of Historical Geography, vol. 39, pp. 19-28, 2012.

[54] Xiong'an China, " 213 items of intangible cultural heritage in Xiong'an new area," 2017, http://www.xiongan.gov.cn/201712/20/c_129771061.htm. 